\title{
Simulation of Motion Behavior of Concrete in Pump Pipe by DEM
}

\author{
Ji Hao $\mathbb{D}^{1,2}$ Caiyun Jin $\mathbb{D},{ }^{3}$ Yue Li, ${ }^{1}$ Zigeng Wang, ${ }^{1}$ Jianglin Liu $\mathbb{D},{ }^{1}$ and Hongwen Li $\mathbb{D}^{1}$ \\ ${ }^{1}$ The Key Laboratory of Urban Security and Disaster Engineering, Beijing University of Technology, Beijing 100124, China \\ ${ }^{2}$ Department of Material Science and Engineering, Beijing University of Technology, Beijing 100124, China \\ ${ }^{3}$ College of Applied Sciences, Beijing University of Technology, Beijing 100124, China
}

Correspondence should be addressed to Caiyun Jin; jincaiyun@bjut.edu.cn

Received 14 April 2021; Accepted 13 May 2021; Published 26 May 2021

Academic Editor: Guoming Liu

Copyright (C) 2021 Ji Hao et al. This is an open access article distributed under the Creative Commons Attribution License, which permits unrestricted use, distribution, and reproduction in any medium, provided the original work is properly cited.

\begin{abstract}
In this paper, the mesocalibration test was used to measure the contact parameters (restitution coefficient, rolling friction coefficient, static friction coefficient, and surface energy) between coarse aggregate particles and mortar particles in Discrete Element Method (DEM) model of concrete. Then, the DEM model of concrete slump was established according to the coarse aggregate gradation to study the flow behavior of coarse aggregate in fresh concrete. The slump test result was compared with the output of the slump DEM model with high consistent, indicating the promising reliability of the mesocalibration test. Finally, based on the mesocalibration test results, the DEM model of pumping concrete was established. It was obtained that the pumping pressure calculated by the numerical model was similar to that of the pumping test with satisfactory accuracy better than the concrete pumping pressure calculated according to the rheological test results of concrete and lubricating layer. On this basis, the movement trajectory of coarse aggregate in the pump pipe was analyzed and the influence of coarse aggregate on the pumping performance of concrete was revealed.
\end{abstract}

\section{Introduction}

Fresh concrete is a kind of heterogeneous and multiphase composite material with highly inhomogeneous composition and structure $[1,2]$. In fresh concrete, mortar showed non-Newtonian flow behavior, while coarse aggregate showed discrete particle flow behavior [3]. The movement behavior of coarse aggregate in concrete was an important factor affecting the fluidity and pumpability $[4,5]$. In the concrete flow process, there are very complex interactions between the components [6]. Accurate understanding of the flow behavior of fresh concrete is a necessary prerequisite for normal construction and improvement of hardening properties of concrete [7]. In order to deeply study the flow performance of fresh concrete, numerical simulation had become a common method to study the fluidity of concrete [8]. DEM was a numerical method to simulate the motion behavior of discontinuous media with unique advantages in describing the fluidity of concrete on macroscale and the collision behavior of aggregate particles on mesoscale $[9,10]$. During the pumping process, the movement trajectory and collision behavior of the aggregate were the main factors affecting the pumpability of the concrete [11]. The DEM can be used to truly simulate the flow behavior of the aggregate in the pump pipe [12].

At present, a variety of DEM contact models of fresh concrete have been proposed to simulate the fluidity of fresh concrete. Mechtcherine [13] focused on the algorithm of model parameters related to yield stress and then compared the analytical prediction and numerical prediction of the slump-flow test. Shyshko [14] based on the test results of force-displacement between particles to establish a normal contact model between particles, and the influence of contact parameters on numerical simulation was studied. Remond and Pizette [15] proposed a new "hard-core softshell" DEM model to simulate the rheology and slump of concrete. Hoornahad and Koenders [16] used two-phase paste-bridge system as grain-paste-grain interactions to explore the fluidity of fresh concrete. Li et al. $[17,18]$ proposed a DEM model for predicting the time-dependent fluidity of fresh concrete. Zhang et al. [19] established the normal action constitutive relationship between self- 
compacting concrete particles and then simulated the flow process of rock-filled concrete. Compared with the concrete fluidity test, the DEM simulation can describe the flow behavior of concrete particles at the mesoscopic level. Considering the important factors such as pipeline, aggregate, and pumping conditions, Zhan et al. [20] adopted the DEM to simulate the local pumping of concrete. Tan [21] established the DEM model of concrete by considering the thixotropy of fresh concrete and studied the variation of lateral pressure of concrete to wall with time. Cui et al. $[22,23]$ used irregularly shaped particles as coarse aggregate to study the effect of coarse aggregate size distribution on pump plugging. Cao et al. [24] studied the effect of coarse aggregate volume fraction on yield stress by using the DEM model of fresh concrete, and then they clarified the effect of coarse aggregate volume fraction on pumping pressure and wall wear. Haustein et al. [25] used DEM to study the segregation of concrete particles under pulsating pumping regime.

A variety of DEM contact models suitable for fresh concrete have been proposed, and extensive fluidity simulations have been carried out. However, the fundamental task of DEM simulating fresh concrete has not been solved, that is, the determination of the quantitative relationship between the contact parameters in the concrete DEM model and the properties and proportion of the components in the concrete $[26,27]$. At present, there were two methods to calibrate the contact parameters of DEM [26]. The first method was trial-error, that is, iteratively change the DEM parameter values until the numerical simulation results match the test results to determine the contact parameter values of the DEM model $[28,29]$. However, the simulation results were affected by multiple parameter values, and different parameter combinations may produce the same simulation results $[28,30]$. Therefore, the main problem of trial and error method was that the correctness of parameter combination used in numerical simulation was hard to estimate $[31,32]$. The second method was to measure the mesocontact parameters directly by test (mesocalibration test), then establish DEM model, and compare the simulation results with the test results [33]. The measured results of the mesocalibration test were close to the real contact parameter value [34]. However, due to the great difference in the shape and size of concrete particles, the testing method of contact parameters was still being further improved [16].

This paper established a quantitative relationship between the DEM contact parameters and the properties and proportions of the fresh concrete composition by using the method of mesocalibration test and further studies the flow behavior of concrete particles in the pump pipe. Fresh concrete was regarded as a material composed of discrete coarse aggregates and uniform flowing mortar. This DEM modeling method was called separate single phase element mode [16]. Through a series of mesocalibration tests, the contact parameters of coarse aggregate particles and mortar particles in concrete DEM model were measured, including restitution coefficient, static friction coefficient, rolling friction coefficient, and surface energy. Then the slump DEM model of fresh concrete was established according to the particle size distribution of coarse aggregate with the contact parameters being inputted for slump numerical simulation. The DEM simulation results were compared with the test results to verify the feasibility of using calibration test to measure the contact parameters between fresh concrete particles. Finally, the DEM model of pumping concrete was established, and the simulation results were compared with the pumping test results to analyze the movement behavior of coarse aggregate in the pumping process of concrete. The research roadmap of this paper is shown in Figure 1.

\section{Materials and Test}

\subsection{Materials}

2.1.1. Cementitious Materials. In this paper, P II 42.5 Portland cement, F-type fly ash, S95 ultrafine slag powder, and ultrafine silica fume were used as cementitious materials. For the chemical composition and basic properties of cementitious materials, see Table 1 .

2.1.2. Aggregate. In order to avoid the influence of the shape of aggregate on the accuracy of particle mesoinput parameters, high-precision spherical glass was used as the coarse aggregate of concrete to carry out mesocalibration test, slump test, rheological test, and pumping test, as shown in Figure 2(a). The glass sphere had smooth surface, good wear resistance, and high compressive strength. The particle size error of glass sphere was less than $0.02 \mathrm{~mm}$, the density was $2530 \mathrm{~kg} / \mathrm{m}^{3}$, the shear modulus was $1.97 \mathrm{GPa}$, and Poisson's ratio was 0.25 . The particle size distribution of coarse aggregate is shown in Table 2.

This paper used spherical glass beads as fine aggregates, as shown in Figure 2(b). The density of the glass beads was $2487 \mathrm{~kg} / \mathrm{m}^{3}$, the shear modulus was $1.93 \mathrm{GPa}$, and Poisson's ratio was 0.26 . The particle size distribution of the fine aggregate is shown in Table 3.

2.1.3. Mixture Proportion. The mix ratio of concrete can be divided into three groups, $\mathrm{A}, \mathrm{B}$, and $\mathrm{C}$, according to the amount of cementitious material and water consumption, and each group had three different coarse aggregate contents. Nine concrete mixes for slump test, rheological test, pumping test, and DEM parameter calibration test are shown in Table 4. In this paper, glass sphere of different particle sizes was used to replace sand and gravel with equal volume. The polycarboxylic acid superplasticizer with a water reduction rate of $29 \%$ and a solid content of $16.9 \%$ was used.

\subsection{Concrete Fluidity Test}

2.2.1. Slump Test. The slump test of concrete was carried out according to the standard GB/T 50080-2016 [35]. The lift-off speed of the slump cone was $0.06 \mathrm{~m} / \mathrm{s}$. The slump and slumpflow test results of fresh concrete are shown in Table 5 . Comparing the slump and slump-flow test results of A, B, 


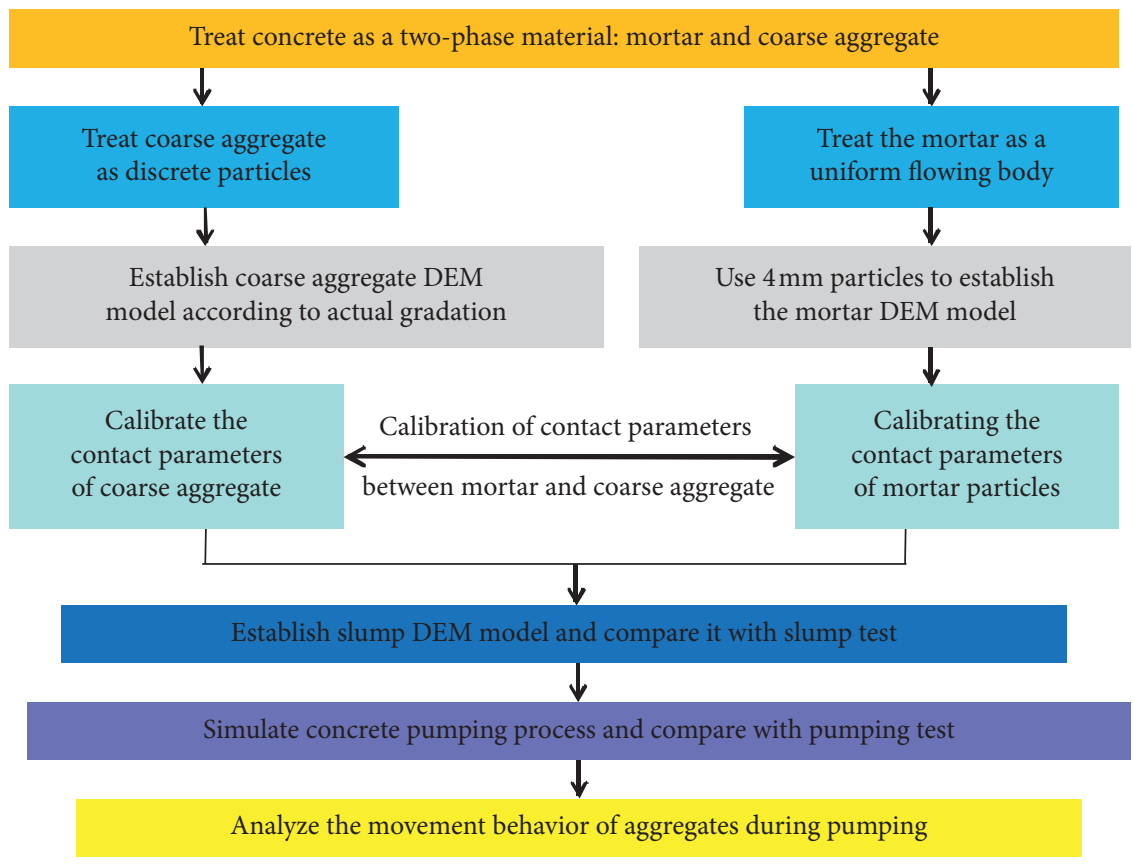

FIgURE 1: Roadmap of this paper.

TABle 1: Chemical compositions and basic properties of cementitious materials (\%).

\begin{tabular}{lcccc}
\hline Chemical composition & Cement & Fly ash & Ultrafine slag & Silica fume \\
\hline $\mathrm{SiO}_{2}$ & 23.6 & 52.3 & 45.7 & 9.8 \\
$\mathrm{Al}_{2} \mathrm{O}_{3}$ & 4.4 & 29.7 & 0.3 & 1.1 \\
$\mathrm{Fe}_{2} \mathrm{O}_{3}$ & 2.3 & 6.5 & 46.6 & 0.7 \\
$\mathrm{CaO}$ & 67.5 & 11.2 & 1.2 & 0.8 \\
$\mathrm{SO}_{3}$ & 2.03 & 1.5 & 0.26 & 0.0 \\
Ignition loss & 4.08 & 3.7 & 2.81 & 4.0 \\
Density g/cm & 3.10 & 2.78 & & 2.20 \\
\hline
\end{tabular}

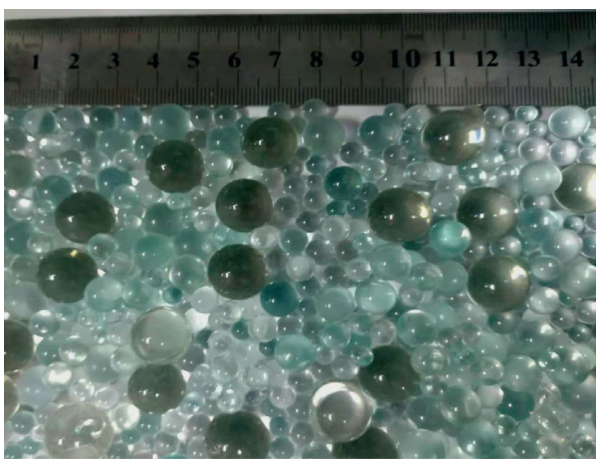

(a)

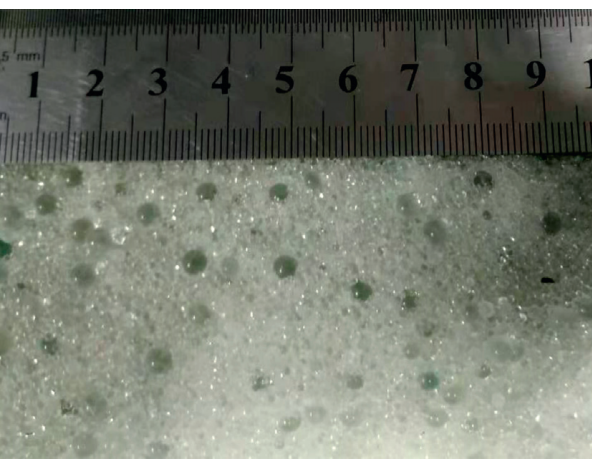

(b)

FIgURE 2: Spherical glass aggregate. (a) Coarse aggregate. (b) Fine aggregate.

TABLE 2: Size distribution of coarse aggregate (\%).

\begin{tabular}{lccccccccccc}
\hline Particle size & $6 \mathrm{~mm}$ & $7 \mathrm{~mm}$ & $8 \mathrm{~mm}$ & $9 \mathrm{~mm}$ & $10 \mathrm{~mm}$ & $11 \mathrm{~mm}$ & $12 \mathrm{~mm}$ & $13 \mathrm{~mm}$ & $14 \mathrm{~mm}$ & $16 \mathrm{~mm}$ \\
\hline Volume percent & 8 & 10 & 10 & 12 & 12 & 11 & 10 & 9 & 8 & 10 \\
\hline
\end{tabular}


TABLe 3: Size distribution of fine aggregate (\%).

\begin{tabular}{lccccccc}
\hline Particle size & $0.15 \mathrm{~mm}$ & $0.30 \mathrm{~mm}$ & $0.60 \mathrm{~mm}$ & $1.18 \mathrm{~mm}$ & $2 \mathrm{~mm}$ & $3 \mathrm{~mm}$ & $4 \mathrm{~mm}$ \\
\hline Volume percent & 8 & 22 & 20 & 12 & 13 & 13 & 12 \\
\hline
\end{tabular}

TABLE 4: Mixture proportions of concrete $\left(\mathrm{kg} / \mathrm{m}^{3}\right)$.

\begin{tabular}{lcccccccccc}
\hline Code & $w / c$ & $\begin{array}{c}\text { Sand } \\
\text { rate }\end{array}$ & Water & Cement & $\begin{array}{c}\text { Fly } \\
\text { ash }\end{array}$ & Slag & $\begin{array}{c}\text { Silica } \\
\text { fume }\end{array}$ & $\begin{array}{c}\text { Fine } \\
\text { aggregate }\end{array}$ & $\begin{array}{c}\text { Coarse } \\
\text { aggregate }\end{array}$ \\
\hline A1 & & 0.41 & 189.0 & 250 & 120 & 60 & 20 & 950 & 1367 & 2.6 \\
A2 & 0.42 & 0.46 & 189.0 & 250 & 120 & 60 & 20 & 950 & 1115 \\
A3 & & 0.51 & 189.0 & 250 & 120 & 60 & 20 & 950 & 910 & 2.6 \\
\hline B1 & & 0.41 & 193.6 & 320 & 150 & 100 & 35 & 780 & 1122 & 3.9 \\
B2 & 0.32 & 0.44 & 193.6 & 320 & 150 & 100 & 35 & 780 & 993 & 3.9 \\
B3 & & 0.47 & 193.6 & 320 & 150 & 100 & 35 & 780 & 890 & 3.9 \\
\hline C1 & & 0.37 & 163.8 & 350 & 130 & 100 & 50 & 647.5 & 1102 & 5.6 \\
C2 & 0.26 & 0.40 & 163.8 & 350 & 130 & 100 & 50 & 647.5 & 971 & 5.6 \\
C3 & & 0.43 & 163.8 & 350 & 130 & 100 & 50 & 647.5 & 858 \\
\hline
\end{tabular}

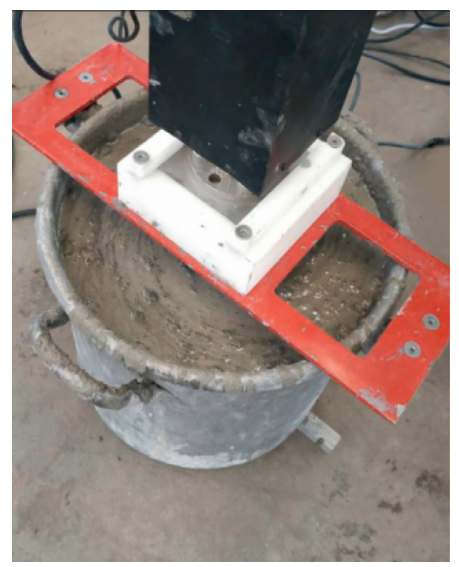

(a)

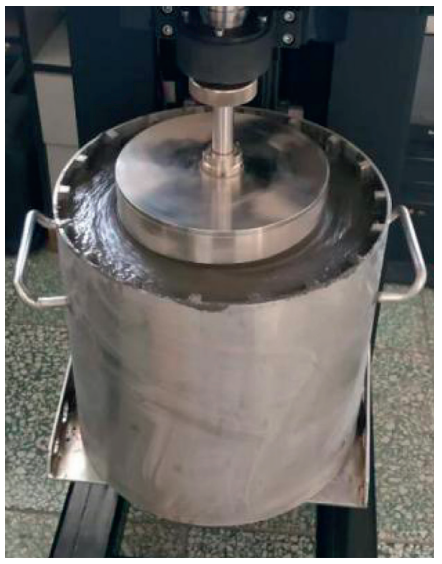

(b)

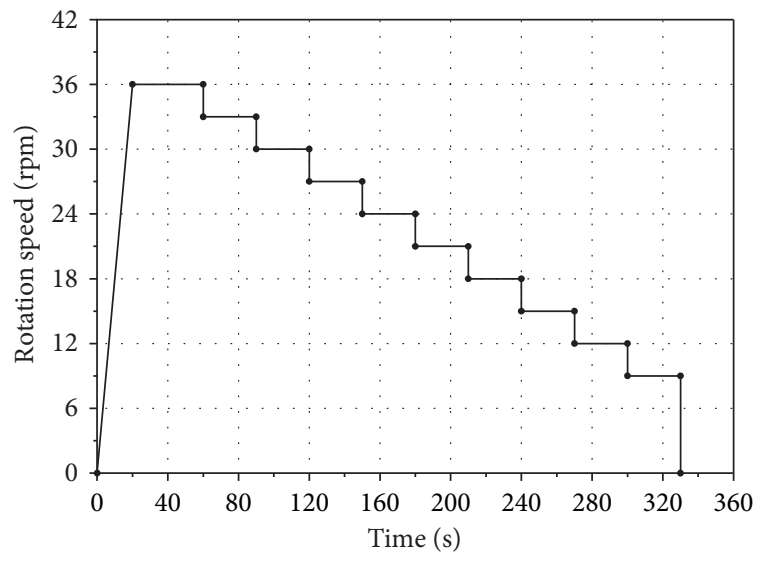

(c)

FIGURE 3: Tribometer and rheometer used to measure rheological properties. (a) ICAR rheometer. (b) TR-CRI tribometer. (c) Test speed of TR-CRI.

TABLE 5: Test results of slump and slump-flow of fresh concrete $(\mathrm{mm})$.

\begin{tabular}{lccccccccc}
\hline & A1 & A2 & A3 & B1 & B2 & B3 & C1 & C2 & C3 \\
\hline Slump & 222 & 224 & 226 & 219 & 221 & 224 & 212 & 215 & 217 \\
Slump-flow & 555 & 561 & 565 & 549 & 551 & 552 & 512 & 516 & 522 \\
\hline
\end{tabular}

TABLE 6: Rheological parameters of lubricating layer and bulk concrete.

\begin{tabular}{lccccccccc}
\hline Parameter & A1 & A2 & A3 & B1 & B2 & B3 & C1 & C2 & C3 \\
\hline$\tau_{0}(\mathrm{~Pa})$ & 21.4 & 20.2 & 19.4 & 28.0 & 26.3 & 25.7 & 37.8 & 35.8 & 33.1 \\
$\mu(\mathrm{Pa} \cdot \mathrm{s})$ & 16.0 & 15.2 & 14.1 & 20.1 & 19.5 & 18.3 & 24.6 & 22.3 & 21.4 \\
$\tau_{0 L L}(\mathrm{~Pa})$ & 10.8 & 10.4 & 10.1 & 12.2 & 11.9 & 11.5 & 14.5 & 13.7 & 13.3 \\
$\mu_{L L}(\mathrm{~Pa} \cdot \mathrm{s})$ & 1.8 & 1.7 & 1.7 & 2.2 & 2.2 & 2.1 & 3.6 & 3.6 & 3.6 \\
\hline
\end{tabular}

and $\mathrm{C}$ of concrete, the influence of glass sphere coarse aggregate content on concrete test result was small, and the flow performance of concrete with the same amount of cementitious material and water consumption was basically similar.
2.2.2. Rheological Test of Concrete and Lubricating Layer. At present, it was generally believed that the rheological properties of concrete and lubricating layer were the key parameters affecting the pumping pressure of concrete, and there was a good correlation between the pressure loss-flow rate of pumped concrete and the rheological parameters of the concrete [5]. It was very difficult to measure the rheological properties of the lubricating layer in the pump pipe directly. Therefore, it was usually made to use "tribometer" to measure the rheological properties of the lubricating layer [36]. In this paper, the yield stress $\tau_{0}$ and plastic viscosity $\mu$ of concrete were measured by ICAR concrete rheometer (see Figure $3(\mathrm{a})$ ). The yield stress $\tau_{O L L}$ and plastic viscosity $\mu_{L L}$ of the lubricating layer between concrete and cylinder wall were measured by TR-CRI tribometer (see Figure 3(b)). The test speed of TR-CRI tribometer is shown in Figure 3(c). Rheological parameters of lubricating layer and bulk concrete are shown in Table 6. The content of coarse aggregate had little effect on the rheological properties of concrete. The yield stress and plastic viscosity of concrete with the same water-cement ratio decreased with the decrease of aggregate 


$\begin{array}{lll}\text { Hertical pipe } & \text { Hertical bend } & \text { Hontal } \\ \text { bend }\end{array}$

FIGURE 4: Schematic ground plan of the pumping test.

TABLE 7: The pumping pressure of concrete in horizontal pipe ( $\mathrm{MPa} / \mathrm{m})$.

\begin{tabular}{lccccccccccc}
\hline & & A1 & A2 & A3 & B1 & B2 & B3 & C1 & C2 & C3 \\
\hline \multirow{2}{*}{ Simulation value } & $0.53 \mathrm{~m} / \mathrm{s}$ & 0.0293 & 0.0286 & 0.0278 & 0.0403 & 0.0396 & 0.0389 & 0.0531 & 0.0526 & 0.0514 \\
& $0.71 \mathrm{~m} / \mathrm{s}$ & 0.0340 & 0.0332 & 0.0326 & 0.0472 & 0.0460 & 0.0448 & 0.0586 & 0.0569 & 0.0553 \\
\hline \multirow{2}{*}{ Test value } & $0.53 \mathrm{~m} / \mathrm{s}$ & 0.0312 & 0.0307 & 0.0301 & 0.0419 & 0.0409 & 0.0403 & 0.0553 & 0.0543 & 0.0537 \\
& $0.71 \mathrm{~m} / \mathrm{s}$ & 0.0367 & 0.0356 & 0.0345 & 0.0491 & 0.0475 & 0.0459 & 0.0612 & 0.0606 & 0.0597 \\
\hline \multirow{2}{*}{ Calculated value } & $0.53 \mathrm{~m} / \mathrm{s}$ & 0.0718 & 0.0679 & 0.0678 & 0.0878 & 0.0877 & 0.0838 & 0.14339 & 0.14335 & 0.14333 \\
& $0.71 \mathrm{~m} / \mathrm{s}$ & 0.0956 & 0.0903 & 0.0903 & 0.1169 & 0.1169 & 0.1115 & 0.19100 & 0.19096 & 0.19094 \\
\hline
\end{tabular}

content. The yield stress and plastic viscosity of the lubricating layer were very little affected by the coarse aggregate content.

2.2.3. Pumping Test. In this paper, a small-scale pumping test was used to measure the pumping pressure of concrete. The pumping test used HBT6006A-5 trailer pump to provide pumping power, and the maximum pump pressure was $7 \mathrm{MPa}$. The pump pipe system consisted of a horizontal straight pipe with a length of $59.65 \mathrm{~m}$, a $180^{\circ}$ horizontal curved pipe with a bending radius of $0.35 \mathrm{~m}$, a $90^{\circ}$ vertical curved pipe with a bending radius of $0.35 \mathrm{~m}$ (used to connect the horizontal pipe and the vertical pipe), and a vertical pipe with a height of $3 \mathrm{~m}$. A $180^{\circ}$ elbow was used at the end of the vertical pipe to connect to the inlet of the trailer pump so that the concrete can be pumped circularly. The layout plan of the pump pipe is depicted in Figure 4. The inner diameter of the pump pipe was $100 \mathrm{~mm}$, and I, II, and III represented the location of the pressure sensors. The average horizontal pushing speed of the piston was $0.53 \mathrm{~m} / \mathrm{s}$ and $0.71 \mathrm{~m} / \mathrm{s}$, and the corresponding concrete pumping flow was $15 \mathrm{~m}^{3} / \mathrm{h}$ and $20 \mathrm{~m}^{3} / \mathrm{h}$. According to the pump pressure difference measured by the pressure sensor, the pump pressure loss $(\mathrm{MPa} / \mathrm{m})$ of the horizontal pipe was calculated, as shown in Table 7.

2.3. Calibration Test. The contact model between concrete particles used the Hertz-Mindlin with JKR (Johnson-Kendall-Roberts) Cohesion model [37]. In the concrete separate single phase element mode, fine aggregate accounted for a large proportion in concrete, which was crucial to the flow and other characteristics of concrete. However, due to the large size distribution of fine aggregate, the pursuit of real particle size distribution of fine aggregate was not of great significance to the study of concrete fluidity and led to excessive consumption of calculation time $[38,39]$. In order to ensure the efficiency of calculation, uniform sphere can be used instead of fine aggregate in DEM model [23, 40]. Gu et al. [41] proposed that the ratio of sample size to average particle size should be greater than
11.5 to avoid possible scale effects. Therefore, the coarse aggregate elements in the DEM model of concrete in this paper used the same particle size distribution as the test, and the mortar elements were represented by spheres of uniform size. In this paper, the DEM model of mortar was composed of particles with a diameter of $4 \mathrm{~mm}$ [31].

The DEM model of concrete included two phases: mortar particle and coarse aggregate particle [16]. In the concrete fluidity test and pumping test, the test equipment material (geometry phase) as the constraining boundary contacted with the mortar particle and coarse aggregate particle. Therefore, in the DEM model, the contact parameters between geometry and mortar particle (MP) and between geometry and coarse aggregate particle (CAP) must be considered. In separate single-phase element mode, there were five groups of contact parameters that needed to be calibrated, including MP-MP, MP-CAP, MP-geometry, CAP-CAP, and CAP-geometry. In the mesocalibration test of mortar particles, the fine aggregate particles of $4 \mathrm{~mm}$ were used as the research object to calibrate the contact parameters of MP-MP, MP-CAP, and MP-geometry. The test equipment material used for fluidity test and calibration test in this paper was stainless steel with a density of $7750 \mathrm{~kg} / \mathrm{m}^{3}$, shear modulus of $72.797 \mathrm{GPa}$, and Poisson's ratio of 0.305 .

2.3.1. Coefficient of Restitution. In this paper, MP-geometry restitution coefficient $\left(e_{m g}\right)$ was measured with reference to Barrios' test [42]; see Figure 5. MP fell freely from a fixed height $H$ and rebounded to the height of $h$ after colliding with the geometry plate [43]. $H$ and $h$ values were recorded with the high-speed camera. $e_{m g}$ can be calculated using

$$
e_{m g}=\sqrt{\frac{h}{H}} .
$$

In the $e_{m g}$ test, the free fall particles were $4 \mathrm{~mm}$ glass spheres wrapped in paste. In the CAP-geometry restitution coefficient $\left(e_{c g}\right)$ test, the free-falling particles were $12 \mathrm{~mm}$ glass spheres wrapped in paste. The geometry plate used in 


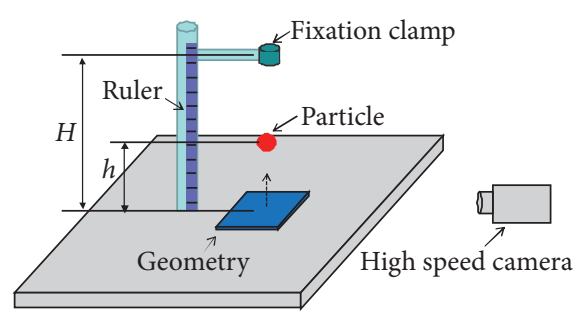

FIgURE 5: Test device for restitution coefficient.

the test was a stainless steel plate of the same material as the slump plate.

In this paper, the MP-MP restitution coefficient $\left(e_{m m}\right)$ test and MP-CAP restitution coefficient $\left(e_{m c}\right)$ test were carried out by using the glass plate with the same material and process as the fine aggregate instead of the impacted particles; that is, the geometry plate in Figure 5 was replaced by the glass plate with the same material as the fine aggregate [44]. The CAP-CAP restitution coefficient $\left(e_{c c}\right)$ test was carried out using glass plates of the same material as the coarse aggregate instead of the impacted particles. The particles were released from four different fixed heights of $100 \mathrm{~mm}, 90 \mathrm{~mm}, 80 \mathrm{~mm}$, and $70 \mathrm{~mm}$ and collided with the plate after free fall. The test was repeated 10 times for each fixed height to obtain the average rebound height $h$.

2.3.2. Coefficient of Rolling Friction. The rolling friction coefficient of concrete particle was measured by inclined test [43], as shown in Figure 6. In the CAP-geometry rolling friction coefficient $\left(\mu_{r-c g}\right)$ test and MP-geometry rolling friction coefficient $\left(\mu_{r-m g}\right)$ test, the same stainless steel plate as the slump plate was used as the inclined plate [44]. In the CAP-CAP rolling friction coefficient $\left(\mu_{r-c c}\right)$ test, the glass plate of the same material as the coarse aggregate was used as the inclined plate. In the MP-MP rolling friction coefficient $\left(\mu_{r-m m}\right)$ test and MP-CAP rolling friction coefficient $\left(\mu_{r-m c}\right)$ test, the glass plate of the same material as the fine aggregate was used as the inclined plate. In the test of measuring the rolling friction coefficient, the mortar particles were tested with glass spheres with particle size of $4 \mathrm{~mm}$, and the coarse aggregate particles were tested with glass spheres with particle sizes of $16 \mathrm{~mm}, 14 \mathrm{~mm}, 12 \mathrm{~mm}$, and $10 \mathrm{~mm}$.

We slowly increased the tilt angle of the inclined plate and recorded the critical rolling friction angle of the particles. The force of the particle on the geometry plate is shown in Figure 7 . The value of $\mu_{r-c g}$ is equal to the tangent of the inclination angle $\left(\theta_{r-c g}\right)$ of the plate [44]:

$$
\mu_{r-c g}=\tan \theta_{r c-c g} .
$$

The test procedures of $\mu_{r-c g}, \mu_{r-m c}, \mu_{r-c c}, \mu_{r-m g}$, and $\mu_{r-m m}$ tests were the same, and the test for each particle size was repeated 10 times to obtain the average critical rolling angle.

2.3.3. Coefficient of Static Friction. The static friction coefficient of concrete particle was measured by inclined test [43], same as rolling friction coefficient test. Bonding three glass aggregates of the same particle size together can prevent the aggregate from rolling before sliding on the inclined plate [45], as shown in Figure 8. In the tests of CAPgeometry static friction coefficient $\left(\mu_{s-c g}\right)$ and MP-geometry static friction coefficient $\left(\mu_{s-m g}\right)$, the same stainless steel plate as the slump plate was used as the inclined plate [44]. In the CAP-CAP static friction coefficient $\left(\mu_{s-c c}\right)$ test, the glass plate of the same material as the CAP was treated as the inclined plate. In the MP-MP static friction coefficient $\left(\mu_{s-m m}\right)$ and MP-CAP static friction coefficient $\left(\mu_{s-m c}\right)$ tests, the glass plate of the same material as the MP was regarded as the inclined plate. The static friction coefficient of particles can be calculated according to the critical sliding angle $\left(\theta_{s-c g}\right)$ [44]:

$$
\mu_{s-c g}=\tan \theta_{s c-c g} .
$$

In the test of measuring the static friction coefficient, the MP were tested with $4 \mathrm{~mm}$ particles, and the CAP were tested with $16 \mathrm{~mm}, 14 \mathrm{~mm}, 12 \mathrm{~mm}$, and $10 \mathrm{~mm}$ particles. The glass aggregate directly extracted from concrete (wrapped with paste) was used as sliding particles to carry out static friction coefficient test. The test procedures of $\mu_{s-c c}, \mu_{s-m c}, \mu_{s-c c}$, $\mu_{s-m g}$, and $\mu_{s-m m}$ were the same. Each particle size test was repeated 10 times to obtain the average critical sliding angle.

2.3.4. Surface Energy. The cohesion between fresh concrete particles was expressed by surface energy $(\gamma)$ [33]. In this paper, the cohesion force $\left(F_{\text {pullout }}\right)$ between fresh concrete particles was determined by inclined test; see Figure 9. For the calculation process, see [43].

The paste on the surface of MP was the same as that on the surface of CAP, so it can be considered that the surface energy of MP was equal to that of CAP $[46,47]$. In the test of measuring surface energy, the coarse aggregate of $16 \mathrm{~mm}$, $14 \mathrm{~mm}, 12 \mathrm{~mm}$, and $10 \mathrm{~mm}$ was used for surface energy test. The surface energy test of each particle size was repeated 10 times to obtain the average value of the critical rolling angle $\left(\theta_{r c}\right)$.

\section{Simulation of Pumping Concrete}

3.1. DEM Contact Model. In this paper, Hertz-Mindlin with JKR Cohesion [37] was used as the contact model of concrete particles. Hertz-Mindlin with JKR cohesion took into account the influence of cohesion in the contact zone of particles, which was suitable for the DEM simulation of wet particles. The JKR model modified the normal force on the basis of the Hertz-Mindlin (no slip) model. The tangential forces of JKR model and Hertz-Mindlin (no slip) model were the same.

Figure 10 is the relationship between the normal force and the overlap between particles in the Hertz-Mindlin model and the JKR model. The negative overlap represented the separation between the two particles. When $\gamma=0$, the normal force of JKR was equal to that of Hertz-Mindlin (no slip) model.

3.2. The Volume of Coarse Aggregate and Mortar. Concrete was regarded as a discontinuous system, consisting of two independent phases, that is, the coarse aggregate of 


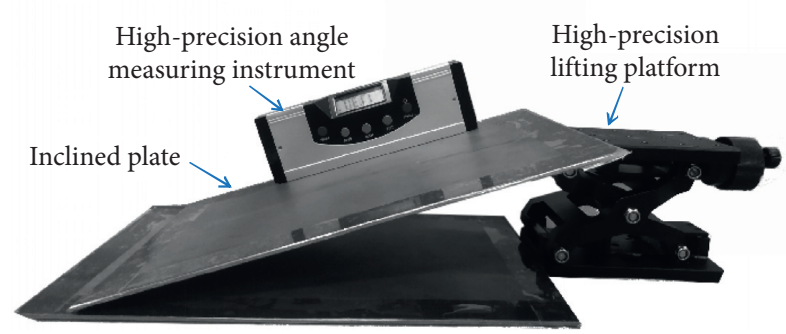

Figure 6: Inclined test device.

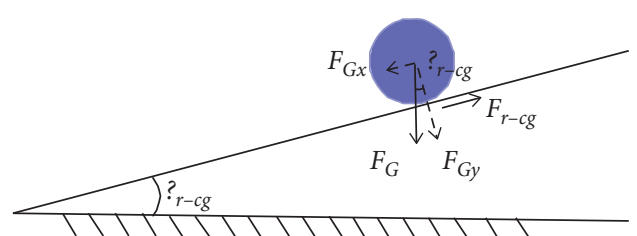

FIgURE 7: Balance of force in rolling friction test.

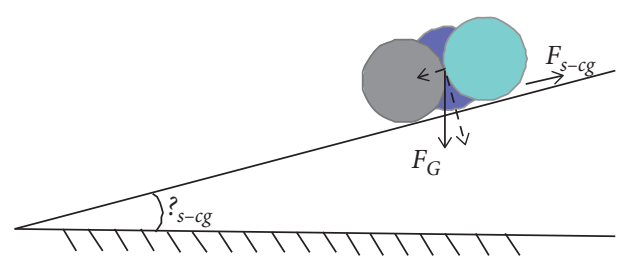

FIGURE 8: Balance of force in static friction test.

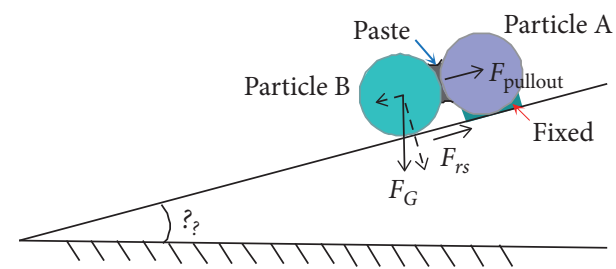

FIGURE 9: Balance of force in $F_{\text {pullout }}$ test.

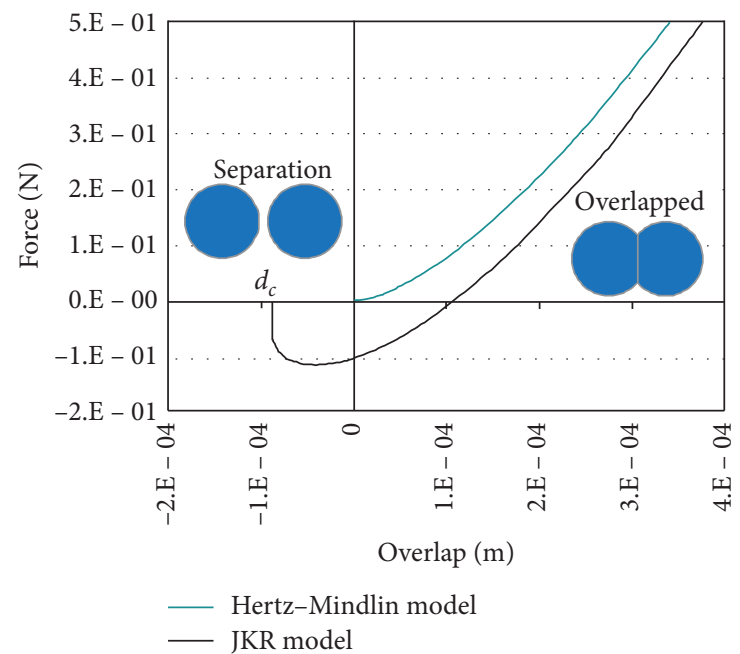

FIGURE 10: The relationship between normal force and overlap in JKR model. solid phase and the mortar of liquid phase (see Figure 11(a)) [49]. In fresh concrete, the paste wrapped around the aggregate moved with the aggregate, so the paste around the aggregate needed to be taken into account when calculating the volume fraction of coarse aggregate particles in the DEM model [19]. In this paper, the Excess Paste Theory was used to calculate the volume fraction of coarse aggregate and mortar in the DEM model of fresh concrete. The relative measured value of aggregate packing density in concrete was expressed by coefficient $\zeta$ :

$$
\zeta=\frac{V_{a}}{V_{b}} \leq 1,
$$

where $V_{a}$ is specific aggregate volume; $V_{b}$ is bulk aggregate volume and represents the volume of aggregate (see Figure 11(b)) in the compacted state. The volume of aggregate in compacted state can be calculated according to ASTM C 29 [50].

In the Excess Paste Theory, the volume of paste $V_{p}$ was divided into two parts: void paste $V_{p v}$ and excess paste $V_{\text {pex }}$. When the aggregate was in a compacted state, the void paste was considered to fill in the gap between the aggregates (see Figure 11(b)). The excess paste was the remaining paste part, that is, a layer of paste $\left(\delta_{p e x}\right)$ wrapped around each aggregate particle. The volume fraction $\left(V_{p v}\right)$ of void paste can be calculated by

$$
V_{p v}=\left(\frac{1}{\zeta}-1\right) \cdot V_{a} .
$$

$V_{p v}$ was subtracted from $V_{p}$ to calculate $V_{\text {pex }}$ :

$$
V_{\text {pex }}=V_{p}-V_{p v} .
$$

The aggregate used in this paper was spherical aggregate. Specific aggregate volume $\left(V_{a}\right)$ and excess paste $\left(V_{\text {pex }}\right)$ were calculated by

$$
\begin{aligned}
V_{a} & =\frac{4 \pi}{3} \sum N_{i} R_{i}^{3}, \\
V_{\text {pex }} & =\frac{4 \pi}{3} \sum N_{i}\left(\left(R_{i}+\delta_{\text {pex }}\right)^{3}-R_{i}^{3}\right),
\end{aligned}
$$

where $R_{i}$ is the radius of aggregate and $N_{i}$ is the number of aggregates in part $i$.

After determining the aggregate particle gradation, the Klein method can be used to calculate the thickness of the remaining paste layer $\left(\delta_{\text {pex }}\right)$ [51]. The $\delta_{\text {pex }}$ was proportional to the radius $R_{i}$ of aggregate, calculated according to (9). In this equation, $\varphi_{\text {pex }}$ was a constant, calculated by (10). It should be ensured that the minimum diameter of aggregate was greater than the minimum value of $\delta_{\text {pex }}$, so as to provide a more accurate range for $\delta_{\text {pex }}[48]$.

$$
\begin{aligned}
& \delta_{\text {pex }}=R_{i} \cdot\left(1+\varphi_{\text {pex }}\right)-R_{i}, \\
& \varphi_{\text {pex }}=1-\sqrt[3]{1-\frac{V_{p}}{V_{a}}} .
\end{aligned}
$$




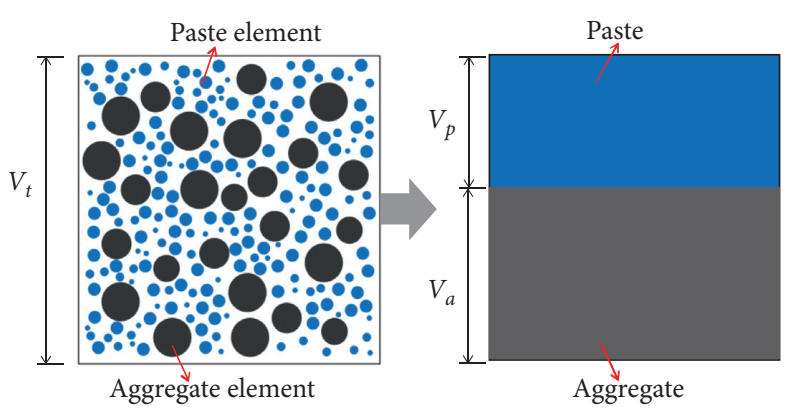

(a)

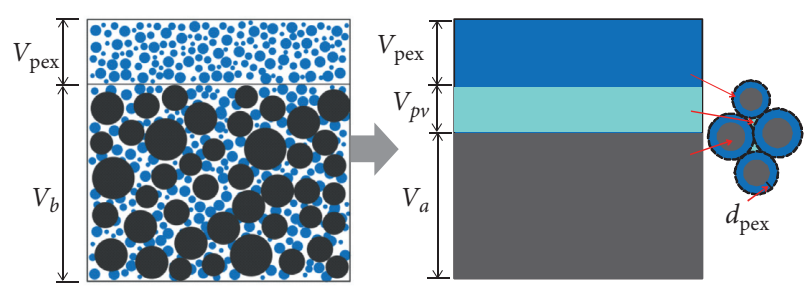

(b)

Figure 11: Schematic of Excess Paste Theory: (a) the real system; (b) the volume of each part of the system in a compacted state and excess paste thickness [48].

In the DEM model of fresh concrete, the volume of coarse aggregate $\left(V_{c}\right)$ and the volume of mortar $\left(V_{m}\right)$ were calculated by

$$
\begin{gathered}
V_{c}=V_{a}+V_{\text {pex }}, \\
V_{m}=V_{t}-V_{c},
\end{gathered}
$$

where $V_{t}$ is the total volume of concrete.

\subsection{Results of Calibration Test}

3.3.1. The Test Results of Restitution Coefficient. The restitution coefficient test results of B1 concrete are shown in Figure 12(a). The rebound height $h$ decreased with the decrease of fixed height $H$. The restitution coefficient was calculated according to (1), and the values of restitution coefficient measured at different fixed heights were basically the same. The average restitution coefficients of nine kinds of concrete particles were calculated according to the fixed height $H$ and rebound height $h$ measured by the test, as displayed in Figure 12(b). The coefficient of restitution of concrete particles increased with the increase of waterbinder ratio, the restitution coefficient of group $A>$ the restitution coefficient of group $B>$ the restitution coefficient of group C. The recovery coefficient was less affected by coarse aggregate content, and the restitution coefficient of concrete with different coarse aggregate content was basically the same.

3.3.2. The Test Result of Rolling Friction Coefficient. According to the critical rolling angle $\left(\theta_{r c}\right)$ measured by the inclining test, the rolling friction coefficient of B1 concrete was calculated, as shown in Figure 13(a). The average value of $\mu_{r-c g}$ of B1 concrete was 0.083 , the average value of $\mu_{r-m c}$ was 0.063 , the average value of $\mu_{r-c c}$ was 0.062 , the average value of $\mu_{r-m g}$ was 0.086 , and the average value of $\mu_{r-m m}$ was 0.084 . The average rolling friction coefficients of nine kinds of concrete particles are displayed in Figure 13(b). The rolling friction coefficient of concrete particles increased with the decrease of water-binder ratio, the rolling friction coefficient of group $\mathrm{A}<$ the rolling friction coefficient of group $\mathrm{B}<$ the rolling friction coefficient of group $\mathrm{C}$. The rolling friction coefficient was less affected by the coarse aggregate content.

3.3.3. The Test Result of Static Friction Coefficient. The static friction coefficient test results of B1 concrete are shown in Figure 14(a). The average values of $\mu_{s-c g}, \mu_{s-m c}, \mu_{s-c c}, \mu_{s-m g}$, and $\mu_{s-m m}$ were $0.178,0.163,0.162,0.181$, and 0.182 , respectively. Figure 14(b) exhibits the average static friction coefficient of nine kinds of concrete. The effect of water-binder ratio on the static friction coefficient of concrete particles was similar to that of the rolling friction coefficient. The static friction coefficient of group $\mathrm{A}<$ the static friction coefficient of group $\mathrm{B}<$ the static friction coefficient of group $\mathrm{C}$. The content of coarse aggregate had little effect on the static friction coefficient of concrete particles, and the static friction coefficient of concrete with different coarse aggregate content was basically the same.

3.3.4. The Test Result of Surface Energy. The test results of critical rolling angle $\left(\theta_{\gamma c}\right)$ of B1 concrete are shown in Figure 15. According to the test results of the inclined test in Figure 9 , the average surface energy $(\gamma)$ of 9 kinds of concrete was calculated by the method in [43]. The surface energy $(\gamma)$ of $\mathrm{A} 1, \mathrm{~A} 2, \mathrm{~A} 3, \mathrm{~B} 1, \mathrm{~B} 2, \mathrm{~B} 3, \mathrm{C} 1, \mathrm{C} 2$, and $\mathrm{C} 3$ is $0.368 \mathrm{~J} / \mathrm{m}^{2}$, $0.368 \mathrm{~J} / \mathrm{m}^{2}, 0.369 \mathrm{~J} / \mathrm{m}^{2}, 0.374 \mathrm{~J} / \mathrm{m}^{2}, 0.374 \mathrm{~J} / \mathrm{m}^{2}, 0.373 \mathrm{~J} / \mathrm{m}^{2}$, $0.383 \mathrm{~J} / \mathrm{m}^{2}, 0.384 \mathrm{~J} / \mathrm{m}^{2}$, and $0.383 \mathrm{~J} / \mathrm{m}^{2}$, respectively.

\subsection{Establishment of the DEM Model of Pumping Concrete}

3.4.1. DEM Model of Slump Test. The slump DEM model was established in accordance with the actual size of the slump cone, and then the density, shear modulus, and Poisson's ratio of the test equipment materials were input. This paper used EDEM software to establish a concrete separate single-phase element mode [16], which regarded concrete as being composed of coarse aggregate wrapped by paste and fine aggregate wrapped by paste. The particle size gradation of CAP was generated in accordance with Table 2. The MP was represented by using $4 \mathrm{~mm}$ particles. Then the test results of restitution coefficient, rolling friction coefficient, static friction coefficient, and surface energy in Section 3.3 were inputted into the concrete DEM model as the 


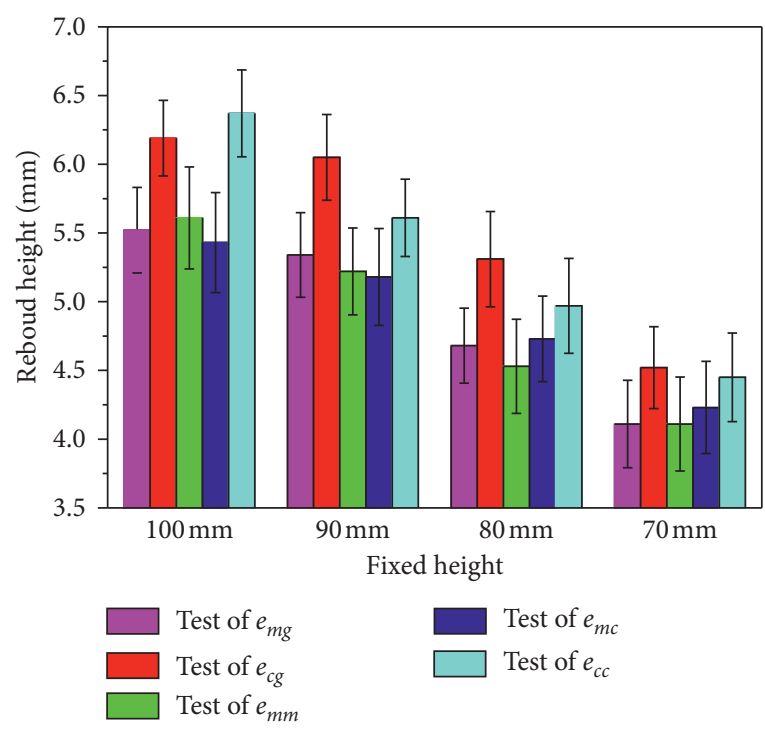

(a)

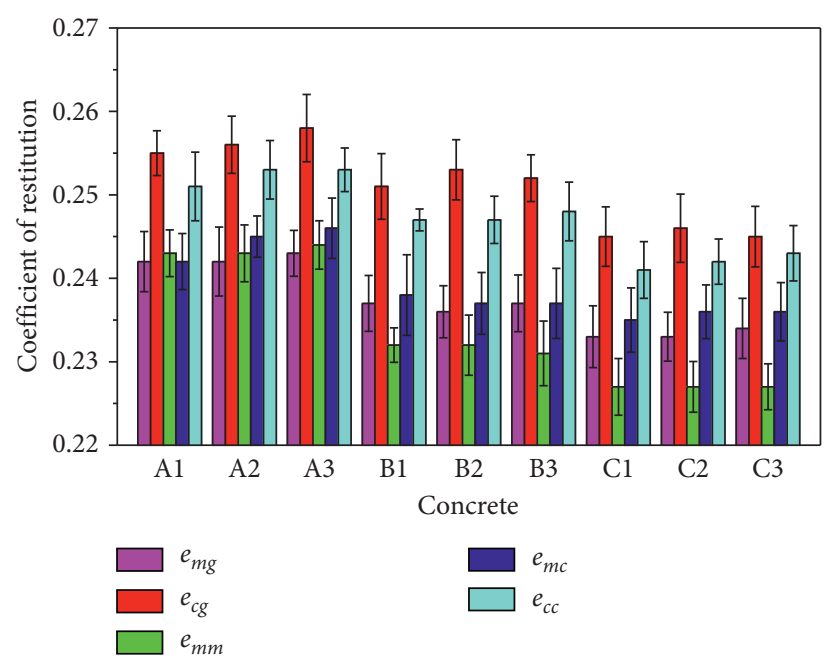

(b)

Figure 12: The test results of restitution coefficient. (a) The restitution coefficient test results of B1 concrete. (b) The restitution coefficient test results of nine kinds of concrete.

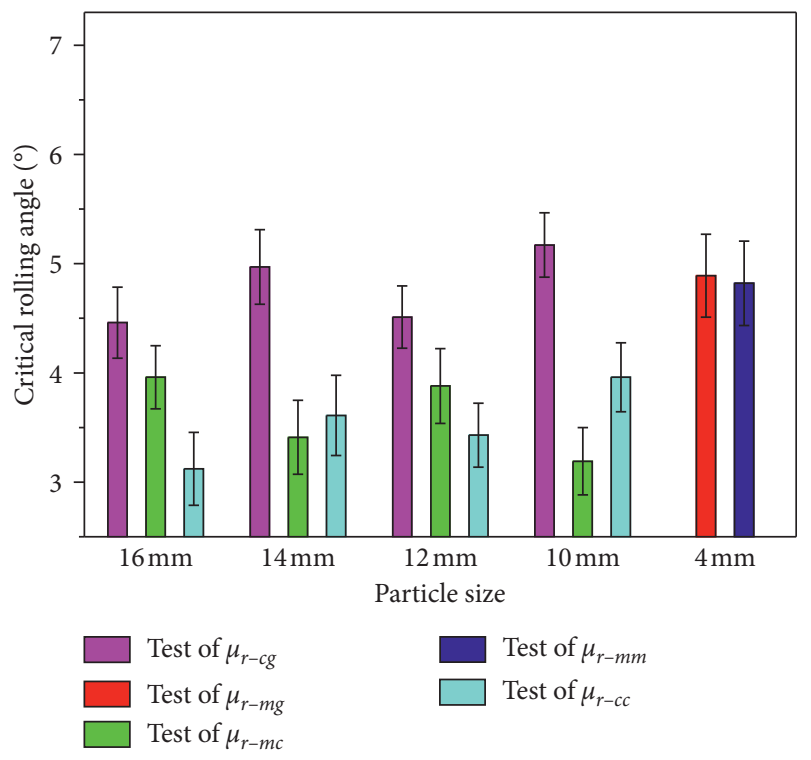

(a)

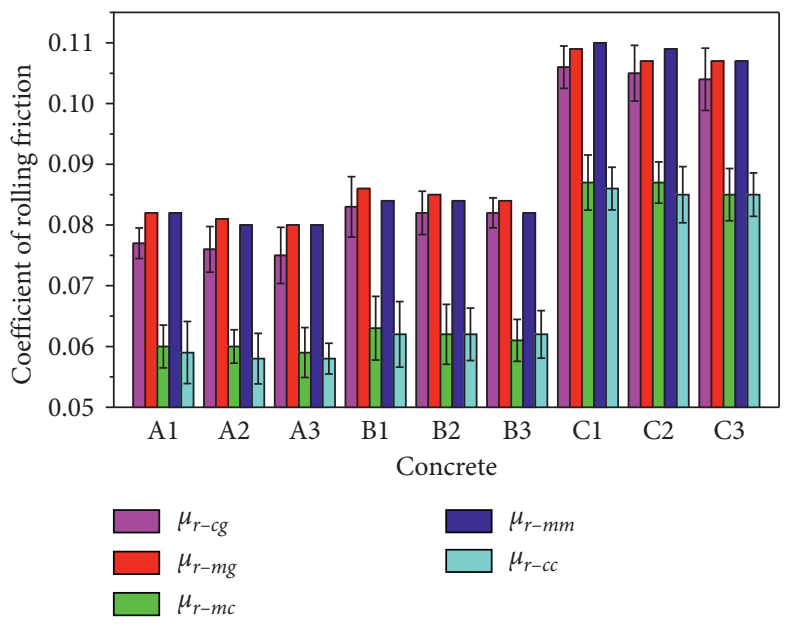

(b)

FIGURE 13: The test results of rolling friction coefficient. (a) The rolling friction coefficient test results of B1 concrete. (b) The rolling friction coefficient test results of nine kinds of concrete.

contact parameters of CAP-MP, CAP-CAP, MP-MP, CAPgeometry, and MP-geometry. Finally, the CAP and MP of concrete were generated in the slump cone.

3.4.2. DEM Model of Pumping Concrete. In the process of concrete entering from the horizontal pipe through the curved pipe to the vertical pipe, the flow pattern of concrete particles in the pump pipe changes greatly. In this paper, the local pumping test was selected for DEM simulation to study the flow behavior of concrete in the process of passing through the bend pipe. The pumping concrete model based on DEM with detailed configuration is shown in Figure 16. The pump pipe consisted of a horizontal pipe that is $3200 \mathrm{~mm}$ long, a vertical pipe that is $1200 \mathrm{~mm}$ high, and a 90-degree bend pipe (the bending radius of the pipe was $350 \mathrm{~mm}$ ). The inner diameter of pump pipe was $100 \mathrm{~mm}$, and the length of concrete in pump pipe was $935 \mathrm{~mm}$. A piston was set at the entrance of the horizontal pipe. In this paper, the piston was used to push the concrete to realize the 


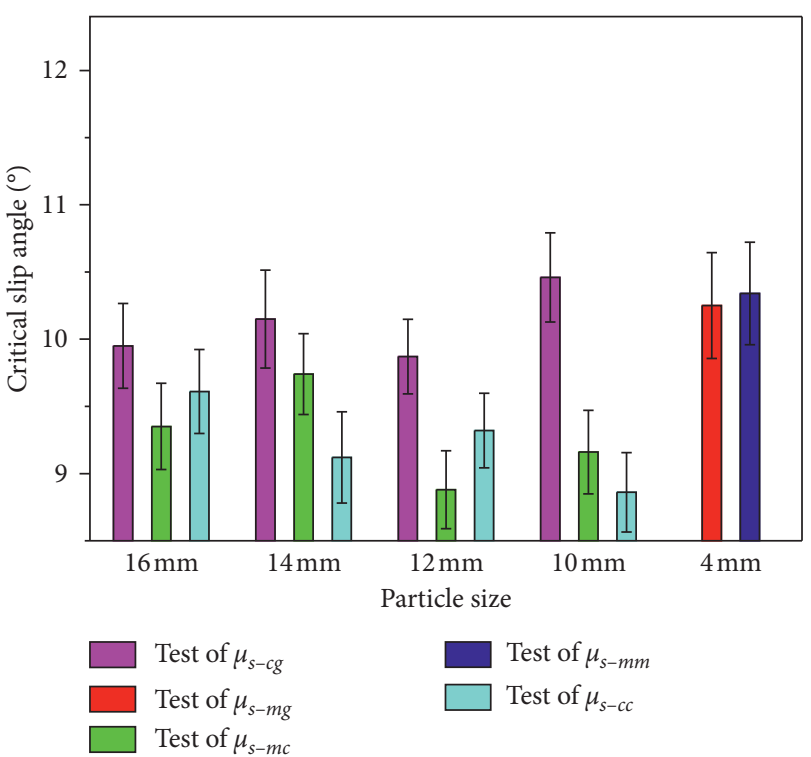

(a)

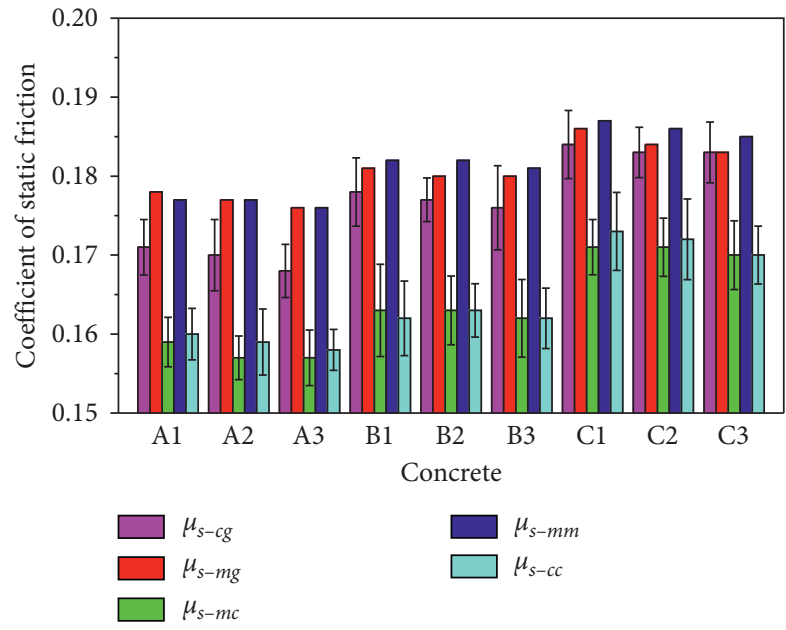

(b)

Figure 14: The test result of static friction coefficient. (a) The static friction coefficient test results of B1 concrete. (b) The static friction coefficient test results of nine kinds of concrete.

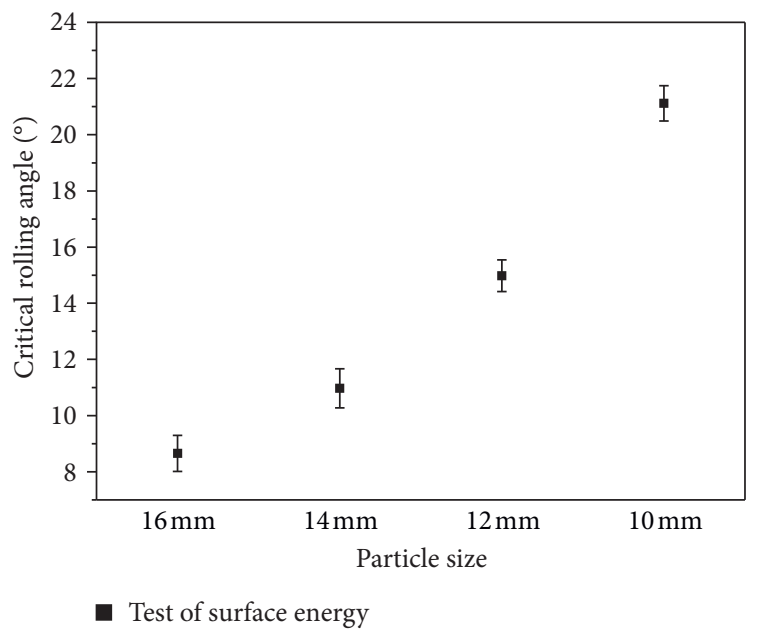

FIgURE 15: The test results of critical rolling angle of B1 concrete.

pumping behavior in the pump pipe. The trajectory of the piston is shown in the "pumping direction" in the figure. In this paper, the pumping concrete simulation was carried out at the speed of $0.53 \mathrm{~m} / \mathrm{s}$ and $0.71 \mathrm{~m} / \mathrm{s}$, and the corresponding pumping flow was $15 \mathrm{~m}^{3} / \mathrm{h}$ and $20 \mathrm{~m}^{3} / \mathrm{h}$.

\section{DEM Simulation Results of Concrete Fluidity}

4.1. DEM Simulation Results of Slump Test. The slump cone in DEM was lifted upward at the speed of $0.06 \mathrm{~m} / \mathrm{s}$. Figure 17 shows the process of $\mathrm{B} 1$ concrete slump test simulated by DEM. The simulation process of slump DEM can be divided into three stages: when the slump cone started to lift off, the inertial force and cohesive force between concrete particles limited the flow speed of concrete, and the concrete flowed slowly; then, the gravitational potential energy of concrete in the slump cone was rapidly converted into kinetic energy, and the concrete flowed rapidly; finally, under the influence of the friction force of slump plate and the cohesion between particles, the flow velocity of concrete gradually decreased and tended to be stable. The three stages of DEM simulation were highly consistent with the test process.

The simulation results of concrete slump and slump-flow are shown in Table 8. Compared with the slump test results, the relative errors of the slump simulation values were $0.45 \%, 0.00 \%, 0.44 \%, 0.46 \%, 0.00 \%, 0.89 \%, 0.00 \%, 0.47 \%$, and $0.46 \%$; the relative errors of slump-flow simulation values were $0.54 \%, 0.18 \%, 0.35 \%, 0.18 \%, 0.18 \%, 0.20 \%$, $0.19 \%, 0.19 \%$, and $0.00 \%$. The DEM simulation results of concrete slump were highly consistent with the test results, which verified the accuracy of the DEM parameter calibration method used in this paper.

\subsection{DEM Simulation Results of Pumping Concrete}

4.2.1. Pumping Pressure. According to the pressure of B1 concrete particles on the piston in DEM model, the pumping pressure-time curve was drawn, as shown in Figure 18. When the concrete was pumped at the speed of $0.53 \mathrm{~m} / \mathrm{s}$, the pumping pressure of concrete at the initial stage of pumping was not stable; after $0.2 \mathrm{~s}$, the pumping pressure of concrete was basically stable, and the average pumping pressure at this stage was $0.0431 \mathrm{MPa}$; at $4.27 \mathrm{~s}$, the concrete particles began to enter the bend pipe, and the pumping pressure increased rapidly; after $5.31 \mathrm{~s}$, the concrete began to pump out of the bend pipe and into the vertical pipe, and the pumping pressure fluctuated in a relatively large range (the average pumping pressure was $0.4572 \mathrm{MPa}$ ); after $6.04 \mathrm{~s}$, the concrete began to pass through the bend pipe completely, and the pumping pressure decreased slowly; after $7.08 \mathrm{~s}$, the 


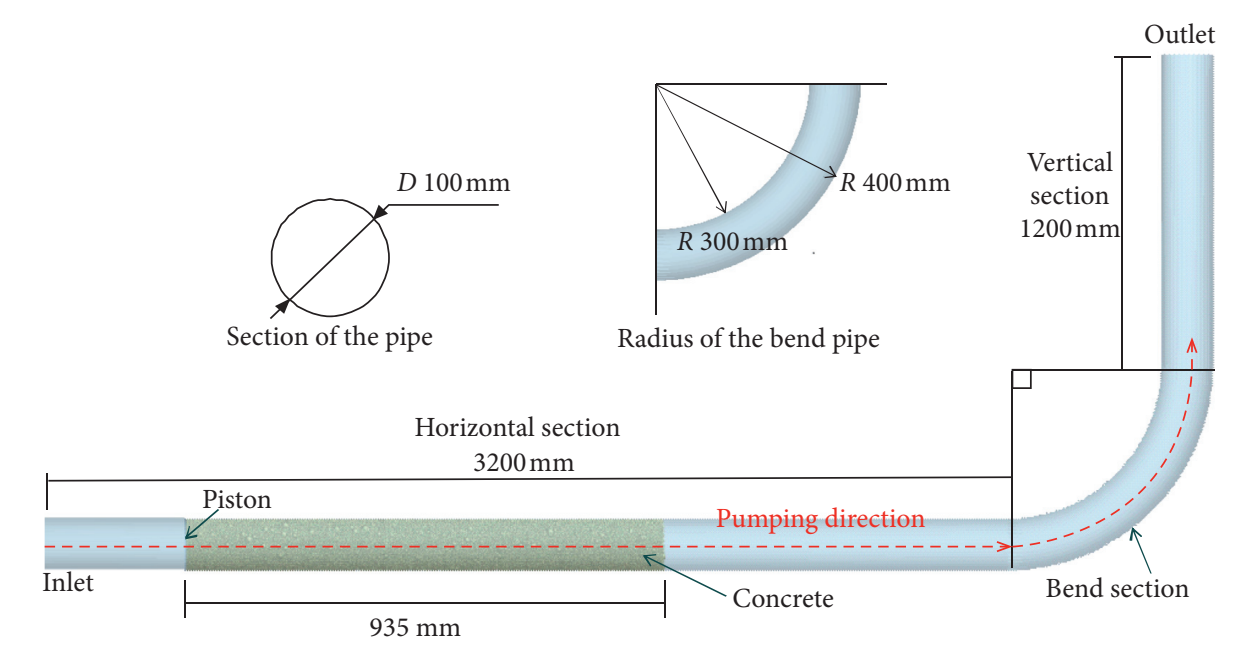

FIGURE 16: DEM model of pumping concrete.

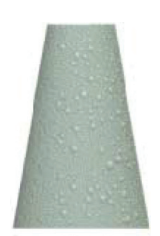

$0 \mathrm{~s}$

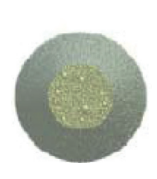

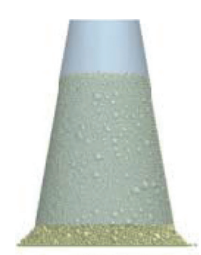

$0.5 \mathrm{~s}$

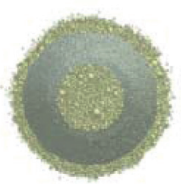

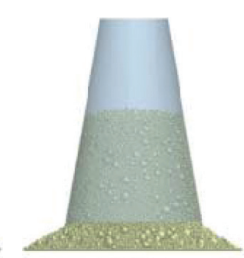

$0.7 \mathrm{~s}$

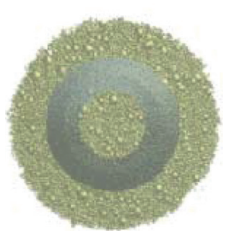

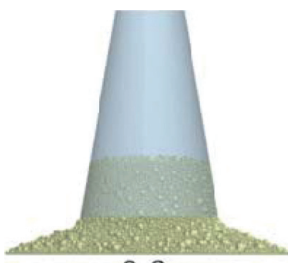

$0.9 \mathrm{~s}$

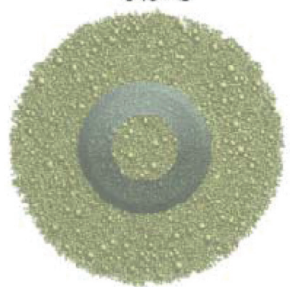

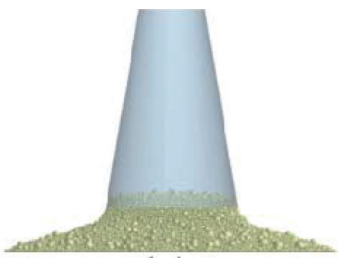

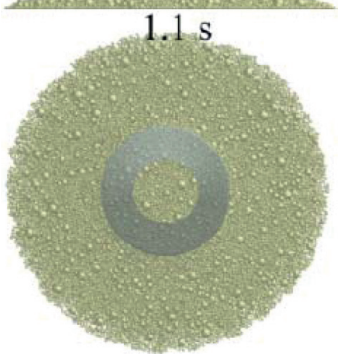

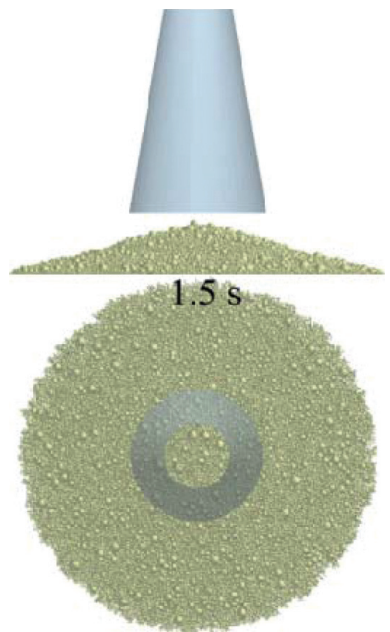

Figure 17: Slump DEM simulation of B1 concrete.

TABLE 8: Simulation results of slump and slump-flow of fresh concrete $(\mathrm{mm})$.

\begin{tabular}{lccccccccc}
\hline & A1 & A2 & A3 & B1 & B2 & B3 & C1 & C2 & C3 \\
\hline Slump & 223 & 224 & 225 & 220 & 221 & 222 & 212 & 214 & 218 \\
Slump-flow & 558 & 560 & 563 & 550 & 552 & 552 & 513 & 517 & 522 \\
\hline
\end{tabular}

concrete completely entered the vertical pipe, and the pumping pressure was relatively stable, with the average pumping pressure of $0.2685 \mathrm{MPa}$. The pumping pressuretime curve of concrete pumping speed of $0.71 \mathrm{~m} / \mathrm{s}$ was similar to that of pumping speed of $0.53 \mathrm{~m} / \mathrm{s}$. The average pumping pressure of concrete with pumping speed of $0.71 \mathrm{~m} / \mathrm{s}$ in horizontal pipe, bend pipe, and vertical pipe was $0.0505 \mathrm{MPa}, 0.5460 \mathrm{MPa}$, and $0.2949 \mathrm{MPa}$, respectively. The pumping pressure of concrete with pumping speed of $0.71 \mathrm{~m} / \mathrm{s}$ in horizontal pipe, bend pipe, and vertical pipe increased by $0.0074 \mathrm{MPa}, 0.0888 \mathrm{MPa}$, and $0.0264 \mathrm{MPa}$, respectively. The pumping pressure of concrete in the horizontal pipe was converted into pressure loss per meter $(\mathrm{MPa} / \mathrm{m})$, as shown in Table 7.
According to the rheological test results of concrete and lubricating layer in Table 6 , the pumping pressure $\mathrm{P}(\mathrm{Pa})$ of concrete in pump pipe was calculated by $(13)[52,53]$ with the values shown in Table 7:

$$
P=\frac{2 L}{R}\left[\tau_{0 L L}+\frac{Q / \pi R^{2} k-R / 4 \mu \tau_{0 L L}+R / 3 \mu \tau_{0}}{1+R / 4 \mu \cdot \mu_{L L} / e} \cdot \frac{\mu_{L L}}{e}\right],
$$

where $\tau_{O L L}$ is the interface yield stress measured with a "tribometer", $\mathrm{Pa} ; \tau_{0}$ is the yield stress of the bulk concrete, $\mathrm{Pa} ; \mu$ is plastic viscosity of the bulk concrete measured by the viscometer, Pa.s; $\mu_{L L}$ is theoretical plastic viscosity of the lubricating layer, Pa.s; $e$ is thickness of the lubricating layer, the value equal to $3 \mathrm{~mm}[36,54], \mathrm{mm}$; $k$ represents the pipefilling coefficient; $R$ is the pipe radius, $\mathrm{m} ; L$ is the pipe length, $\mathrm{m} ; \mathrm{Q}$ is the pumping flow rate of concrete, $\mathrm{m}^{3} / \mathrm{s}$.

According to the pumping pressure difference of pressure sensors I and II in the pumping test in Figure 4, the pumping pressure loss of the horizontal pipe was calculated, as shown in Table 7. The amount of cementitious material, water consumption, and pumping speed had great influence 


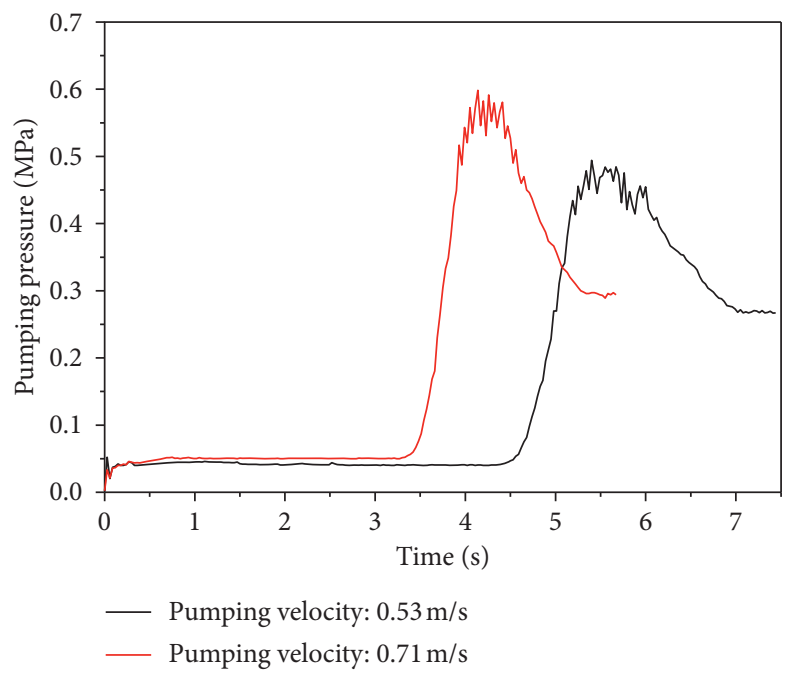

FIGURE 18: The DEM simulation results of B1 concrete pumping pressure.

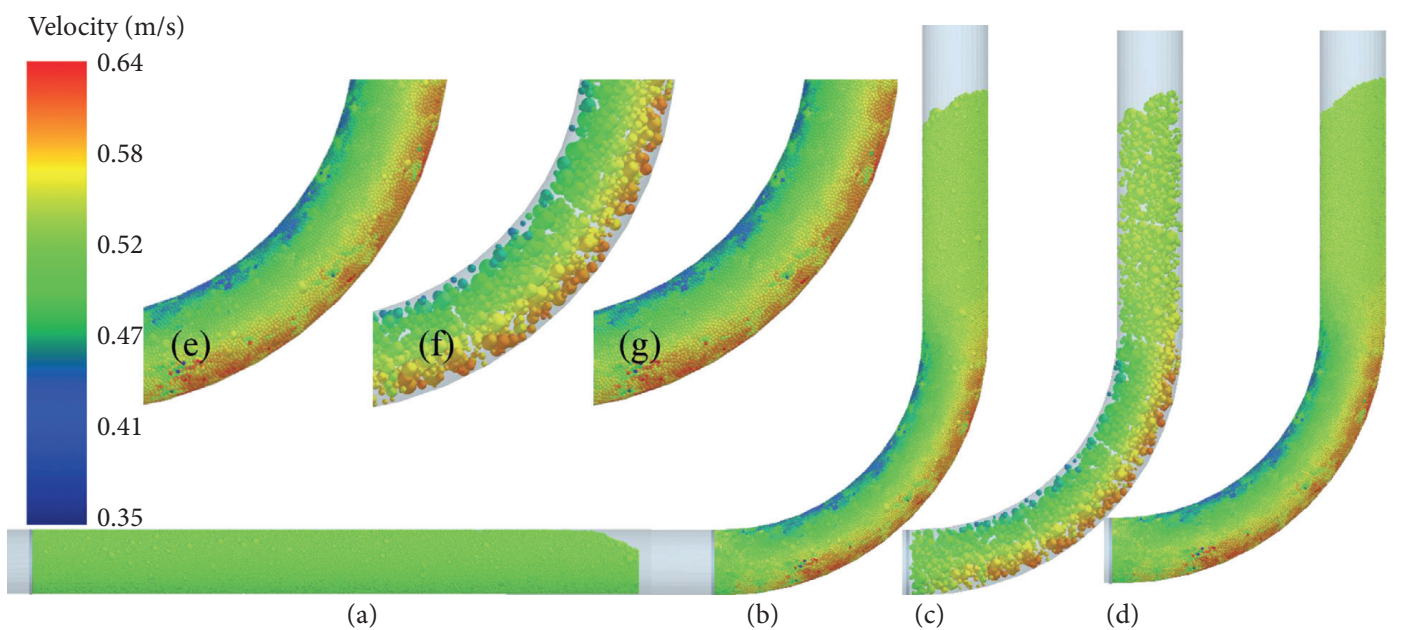

FIGURE 19: Velocity distribution nephogram of B1 concrete in pump pipe. (a) Concrete in horizontal pipe. (b) Concrete in bend pipe. (c) CAP in bend pipe. (d) MP in bend pipe. (e), (f), and (g) are local enlarged views of (b), (c), and (d), respectively.

on the pumping pressure of concrete, while the content of coarse aggregate had little effect on the pumping pressure of concrete. The relative error between the simulation value and the test result was $4.59 \%$, and the relative error between the calculated value and the test result was $152.71 \%$. The simulation result was obviously better than the calculation value.

4.2.2. Movement Behavior Analysis of Aggregate in Pump Pipe. The velocity distribution nephogram of B1 concrete with pumping speed of $0.53 \mathrm{~m} / \mathrm{s}$ in the pump pipe is shown in Figure 19. In the horizontal pipe, the flow velocities of CAP and MP were basically the same; see Figure 19(a). After the concrete entered the bend pipe, the velocity of concrete near the back of the bend pipe was higher, while that near the inner side of the bend pipe was lower (Figure 19(b)). The velocity change of CAP near the back of the bend pipe was more obvious than that of the MP, and the velocity change of the MP near the inner side of the bend pipe was more obvious than that of the CAP; see Figures 19(c) and 19(d), which changed the relative spatial distribution of the CAP in the pump pipe.

When the concrete in the pump pipe kept stable flow state, the relative spatial distribution position of particles was relatively fixed, that is, the contact number between particles kept in a relatively stable range. When the flow state of concrete in the pump pipe changed, the relative spatial distribution position of concrete particles also changed, which led to the change of the contact number between particles. In this paper, the contact number between particles was adopted to evaluate the flow state of concrete in the pump pipe. Figure 20 shows the flow state of CAP and MP in the pump pipe of $\mathrm{B} 1$ concrete at the pumping speed of $0.53 \mathrm{~m} / \mathrm{s}$. Figure 20(a) shows the contact number of CAPCAP and CAP-pipe. The state of CAP fluctuated greatly at the beginning of pumping; after $1.5 \mathrm{~s}$, it gradually stabilized, 


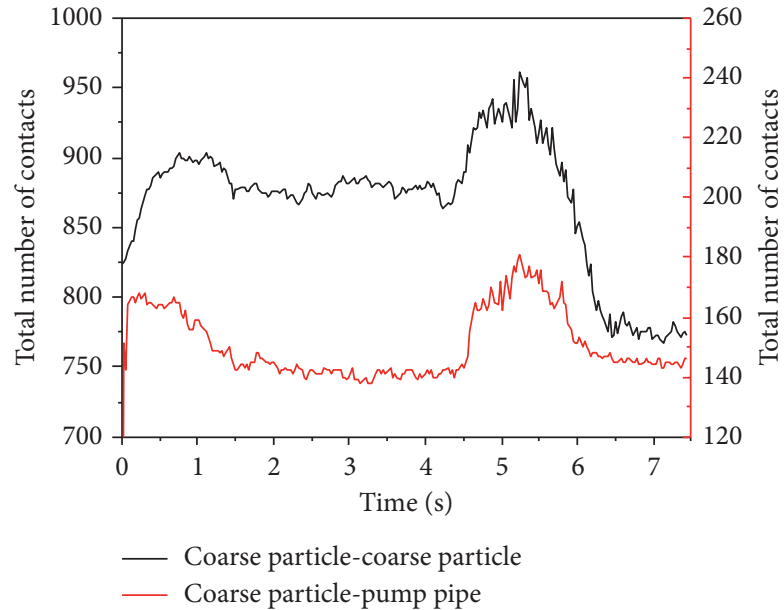

(a)

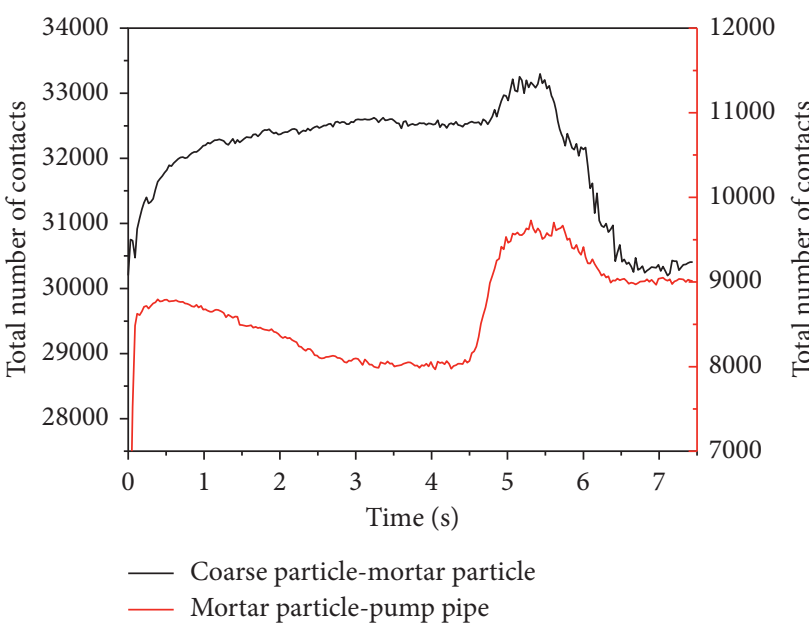

(b)

Figure 20: Contact number of B1 concrete particle in pump pipe. (a) Contact number of CAP-CAP and CAP-pump pipe. (b) Contact number of CAP-MP and MP-pipe.

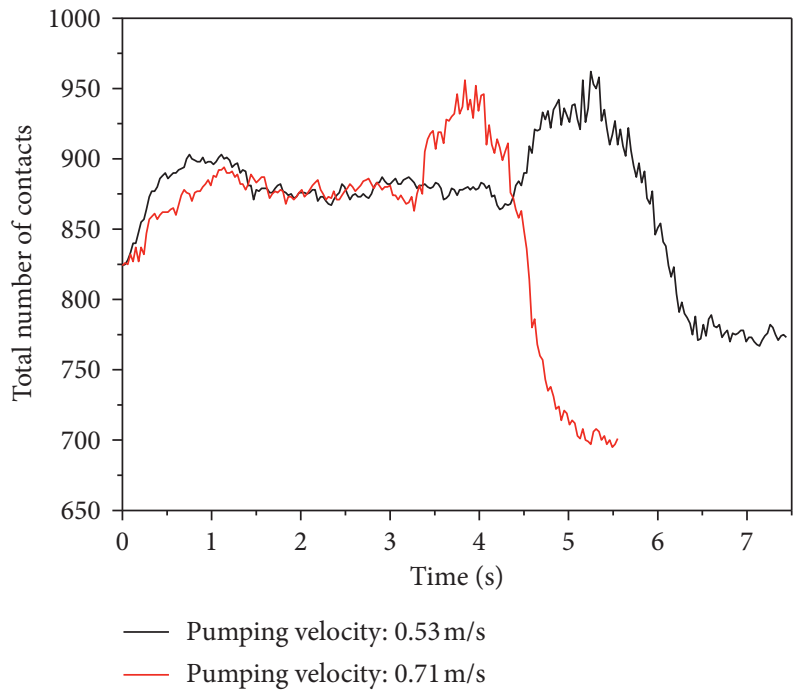

(a)

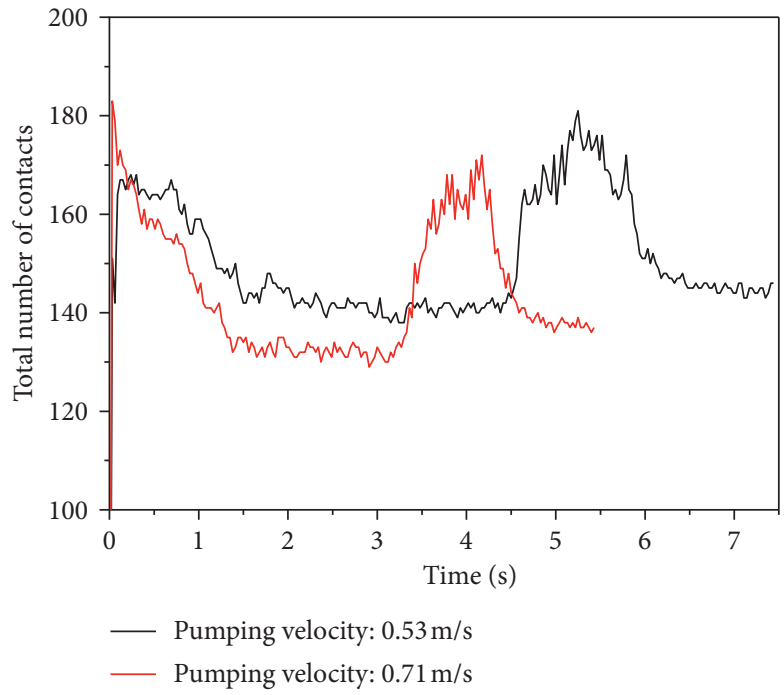

(b)

FIGURE 21: Influence of pumping speed on coarse aggregate movement in pump pipe. (a) Contact number of CAP-CAP. (b) Contact number of CAP-pipe.

and the average contact number of CAP-CAP was about 875; at $4.27 \mathrm{~s}$, the concrete particles began to enter the bend pipe, and the contact number of CAP-CAP increased rapidly; at $5.25 \mathrm{~s}$, the contact number reached the maximum value (962); after $5.31 \mathrm{~s}$, the concrete began to pump out of the bend pipe, and the contact number of CAP-CAP began to decrease rapidly; after $6.04 \mathrm{~s}$, the concrete began to pass through the bend completely, and the contact number decreased slowly and stably; after $7.08 \mathrm{~s}$, the concrete completely entered into the vertical pipe, and the contact number of CAP-CAP was stable at about 775. The development trend of the contact number of CAP-Pipe was roughly the same as that of CAP-CAP. When the concrete passed through the bend, the contact number of CAP-pipe and CAP-CAP increased by $20.99 \%$ and $9.04 \%$, respectively. The increase range of CAP-pipe contact number was obviously higher than that of CAP-CAP. The CAP-pipe contact number of concrete after passing through the bend pipe was slightly higher than the CAP-pipe contact number before passing through the bend pipe. However, the CAP-CAP contact number after passing through the bend was significantly lower than the CAP-CAP contact number before passing through the bend. The contact number of MP-pipe after passing through the bend was higher than that before passing through the bend, as shown in Figure 20(b). When the concrete passed through the bend pipe, the contact 


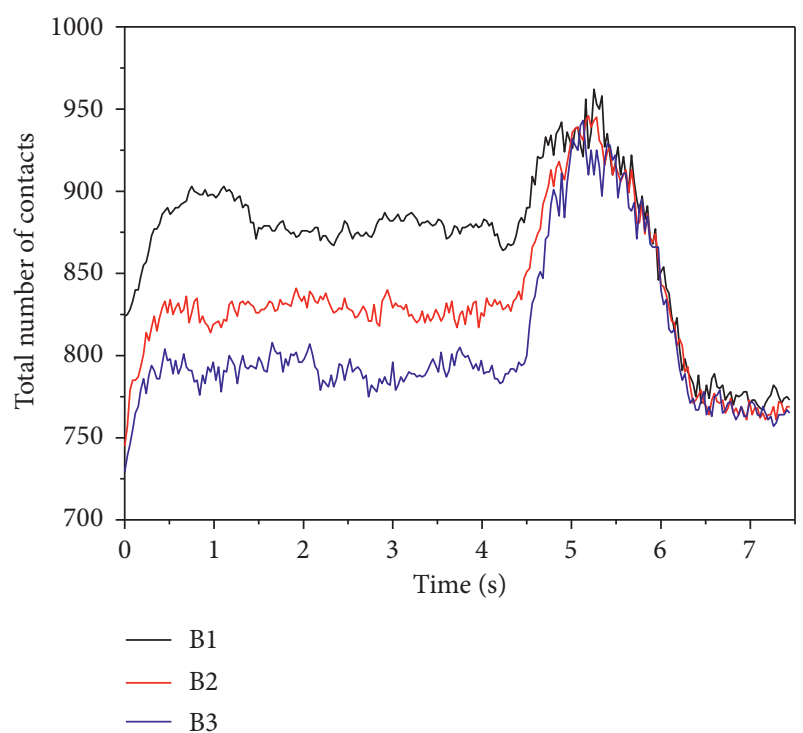

(a)

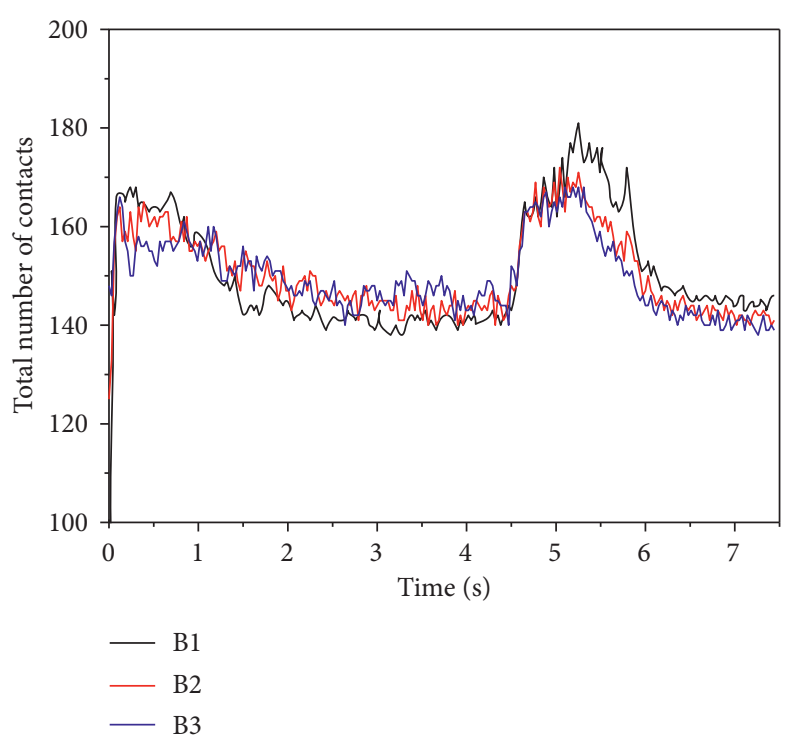

(b)

FIGURE 22: Influence of coarse aggregate content on aggregate movement in pump pipe. (a) Contact number of CAP-CAP. (b) Contact number of CAP-pipe.

number of CAP and MP in concrete changed rapidly, which increased the risk of uneven accumulation of coarse aggregate and pump blockage.

(1) Influence of Pumping Speed on Coarse Aggregate Movement in Pump Pipe. In the horizontal pipe, the average values of the CAP-CAP contact numbers of the $\mathrm{B} 1$ concrete at pumping speeds of $0.53 \mathrm{~m} / \mathrm{s}$ and $0.71 \mathrm{~m} / \mathrm{s}$ were 882 and 881 , respectively, as shown in Figure 21(a). Under the pumping speed of $0.53 \mathrm{~m} / \mathrm{s}$ and $0.71 \mathrm{~m} / \mathrm{s}$, the maximum CAP-CAP contact number of concrete at the bend was 962 and 956, respectively. The pumping speed had little effect on the CAPCAP contact number in the horizontal pipe and bend pipe. After the concrete entered the vertical pipe from the bend pipe, the influence of pumping speed on the coarse aggregate movement behavior increased. At the pumping speed of $0.53 \mathrm{~m} / \mathrm{s}$ and $0.71 \mathrm{~m} / \mathrm{s}$, the CAP-CAP contact number of concrete in the vertical pipe decreased by $18.95 \%$ and $27.37 \%$ compared with the maximum CAP-CAP contact number at the bend pipe, respectively. The pumping speed had a great influence on the CAP-pipe contact number, as shown in Figure 21(b). The CAP-pipe contact number decreased with the increase of pumping speed.

(2) Influence of Coarse Aggregate Content on Aggregate Movement in Pump Pipe. When the pumping speed was $0.53 \mathrm{~m} / \mathrm{s}$, the CAP-CAP contact number of concrete with different coarse aggregate content in the horizontal pipe and in the bend pipe displayed a large difference, as shown in Figure 22(a). The CAP-CAP contact numbers of B1, B2, and B3 concrete in horizontal pipes were 876, 836, and 798, respectively. The CAP-CAP contact numbers decreased with the decrease of coarse aggregate content. After the concrete entered the bend pipe, the CAP-CAP contact numbers of B1, B2, and B3 concrete increased by $19.36 \%, 13.16 \%$, and $18.17 \%$, respectively. After passing through the bend, the
CAP-CAP contact number of the three concretes showed similar changes. When the concrete with different content of coarse aggregate was pumped horizontally, the spatial distribution position of coarse aggregate in the pump pipe was related to the content of coarse aggregate. When the concrete passed through the elbow, the spatial distribution position of coarse aggregate in the pump pipe changed greatly, and this change of distribution position was not affected by the content of coarse aggregate.

The change trend of CAP-Pipe contact number of concrete with different coarse aggregate content was basically the same, as shown in Figure 22(b). The CAP-pipe contact numbers of $\mathrm{B} 1, \mathrm{~B} 2$, and $\mathrm{B} 3$ concrete in the horizontal pipe were 141,144 , and 148 . In the bend pipe, the maximum CAP-pipe contact numbers of $\mathrm{B} 1, \mathrm{~B} 2$, and $\mathrm{B} 3$ concrete were 181,172 , and 168. The CAP-pipe contact numbers of B1, B2, and B3 concrete in the vertical pipe were 144,141 , and 139, respectively. On the whole, the content of coarse aggregate had little effect on the CAP-pipe contact number.

\section{Conclusions}

In this paper, high-precision glass sphere was used as aggregate to prepare fresh concrete. And then slump test, rheological test, and pumping test were carried out, and the slump test and pumping test of concrete were accurately simulated by DEM. Firstly, glass aggregate was used to calibrate the contact parameters of concrete DEM model, and then the slump DEM model was established to verify the reliability of mesocalibration test. Finally, the DEM model of concrete pumping was established, and the influence of pumping speed and aggregate content on concrete pumping was analyzed. According to the test and simulation results, the following conclusions are obtained: 
(1) The influence of high-precision glass coarse aggregate content on slump, rheological properties, and pumping performance of concrete was less than that of cementitious materials and water-binder ratio.

(2) By comparing the slump simulation results with the test results, the mesocalibration test method in this paper can accurately establish the quantitative relationship between concrete mix ratio and DEM contact parameters.

(3) The pumping pressure of concrete simulated by DEM was similar to the test results, and its accuracy was better than that calculated by the rheological properties of concrete and lubricating layer. Moreover, the concrete DEM model can well describe the flow behavior of concrete particles in the pump pipe.

\section{Data Availability}

The data used to support the findings of this study are included within the article.

\section{Conflicts of Interest}

The authors declare that they have no conflicts of interest.

\section{Acknowledgments}

The authors would like to acknowledge the financial support by the National Natural Science Foundation of China (51808015) and National Key R\&D Program of China (2017YFB0310100).

\section{References}

[1] E. Secrieru, D. Cotardo, V. Mechtcherine, L. Lohaus, C. Schröfl, and C. Begemann, "Changes in concrete properties during pumping and formation of lubricating material under pressure," Cement and Concrete Research, vol. 108, pp. 129$139,2018$.

[2] E. Secrieru, W. Mohamed, S. Fataei, and V. Mechtcherine, "Assessment and prediction of concrete flow and pumping pressure in pipeline," Cement and Concrete Composites, vol. 107, p. 103495, 2020.

[3] G. Liu, W. Cheng, L. Chen, G. Pan, and Z. Liu, "Rheological properties of fresh concrete and its application on shotcrete," Construction and Building Materials, vol. 243, p. 118180, 2020.

[4] M. S. Choi, Y. J. Kim, K. P. Jang, and S. H. Kwon, "Effect of the coarse aggregate size on pipe flow of pumped concrete," Construction and Building Materials, vol. 66, pp. 723-730, 2014.

[5] D. Feys, G. De Schutter, K. H. Khayat, and R. Verhoeven, "Changes in rheology of self-consolidating concrete induced by pumping," Materials and Structures, vol. 49, no. 11, pp. 4657-4677, 2016.

[6] Y. W. D. Tay, Y. Qian, and M. J. Tan, "Printability region for 3D concrete printing using slump and slump flow test," Composites Part B: Engineering, vol. 174, p. 106968, 2019.

[7] R. J. Myers, G. Geng, J. Li et al., "Role of adsorption phenomena in cubic tricalcium aluminate dissolution," Langmuir, vol. 33, no. 1, pp. 45-55, 2017.
[8] C. Karakurt, A. O. Celik, C. Yılmazer, V. Kiriççi, and E. Özyaşar, "CFD simulations of self-compacting concrete with discrete phase modeling," Construction and Building Materials, vol. 186, pp. 20-30, 2018.

[9] V. N. Nerella, F. Galvani, L. Ferrara, and V. Mechtcherine, "Normal and tangential interaction between discrete particles immersed in viscoelastic fluids: experimental investigation as basis for Discrete Element Modelling of fresh concrete," in Proceedings of the 8th International RILEM Symposium on Self-Compacting Concrete - SCC 2016, Washingston, DC, USA, May 2016.

[10] V. Mechtcherine, F. P. Bos, A. Perrot et al., "Extrusion-based additive manufacturing with cement-based materials - production steps, processes, and their underlying physics: a review," Cement and Concrete Research, vol. 132, p. 106037, 2020.

[11] P. J. M. Monteiro, G. Geng, D. Marchon et al., "Advances in characterizing and understanding the microstructure of cementitious materials," Cement and Concrete Research, vol. 124, Article ID 105806, 2019.

[12] H. Hoornahad and E. A. B. Koenders, "Tracking the rheological behavior change of a fresh granular-cement paste material to a granular material based on DEM," Advanced Materials Research, vol. 446-449, pp. 3803-3809, 2012.

[13] V. Mechtcherine and S. Shyshko, "Simulating the behaviour of fresh concrete with the Distinct Element Method - deriving model parameters related to the yield stress," Cement and Concrete Composites, vol. 55, pp. 8190, 2015.

[14] S. Shyshko and V. Mechtcherine, "Developing a Discrete Element Model for simulating fresh concrete: experimental investigation and modelling of interactions between discrete aggregate particles with fine mortar between them," Construction and Building Materials, vol. 47, pp. 601-615, 2013.

[15] S. Remond and P. Pizette, "A DEM hard-core soft-shell model for the simulation of concrete flow," Cement and Concrete Research, vol. 58, pp. 169-178, 2014.

[16] H. Hoornahad and E. A. B. Koenders, "Simulating macroscopic behavior of self-compacting mixtures with DEM," Cement and Concrete Composites, vol. 54, pp. 80-88, 2014.

[17] Z. Li, G. Cao, and K. Guo, "Numerical method for thixotropic behavior of fresh concrete," Construction and Building Materials, vol. 187, pp. 931-941, 2018.

[18] G. Cao, Z. Li, and K. Guo, "Analytical study on the change of fluidity of fresh concrete containing mineral admixture with rest time," Journal of Advanced Concrete Technology, vol. 15, no. 11, pp. 713-723, 2017.

[19] X. Zhang, Z. Zhang, Z. Li, Y. Li, and T. Sun, "Filling capacity analysis of self-compacting concrete in rock-filled concrete based on DEM," Construction and Building Materials, vol. 233, p. 117321, 2020.

[20] Y. Zhan, J. Gong, Y. Huang, C. Shi, Z. Zuo, and Y. Chen, "Numerical study on concrete pumping behavior via local flow simulation with discrete element method," Materials, vol. 12, no. 9, pp. 1415-1435, 2019.

[21] Y. Tan, G. Cao, H. Zhang et al., "Study on the thixotropy of the fresh concrete using DEM," Procedia Engineering, vol. 102, pp. 1944-1950, 2015.

[22] W. Cui, W.-s. Yan, H.-f. Song, and X.-l. Wu, "Blocking analysis of fresh self-compacting concrete based on the DEM," Construction and Building Materials, vol. 168, pp. 412-421, 2018.

[23] W. Cui, T. Ji, M. Li, and X. Wu, "Simulating the workability of fresh self-compacting concrete with random polyhedron 
aggregate based on DEM," Materials and Structures, vol. 50, no. 1, pp. 1-12, 2016.

[24] G. Cao, H. Zhang, Y. Tan et al., "Study on the effect of coarse aggregate volume fraction on the flow behavior of fresh concrete via DEM," Procedia Engineering, vol. 102, pp. 1820-1826, 2015.

[25] M. A. Haustein, G. Zhang, and R. Schwarze, "Segregation of granular materials in a pulsating pumping regime," Granular Matter, vol. 21, no. 4, 2019.

[26] C. J. Coetzee, "Review: calibration of the discrete element method," Powder Technology, vol. 310, pp. 104-142, 2017.

[27] S. Shyshko and V. Mechtcherine, "Simulating the workability of fresh concrete," in Proceedings of the International RILEM Symposium on Concrete Modelling, pp. 173-181, Beijing, China, October 2008.

[28] M. Rackl and K. J. Hanley, "A methodical calibration procedure for discrete element models," Powder Technology, vol. 307, pp. 73-83, 2017.

[29] C. J. Coetzee, "Calibration of the discrete element method and the effect of particle shape," Powder Technology, vol. 297, pp. 50-70, 2016.

[30] T. Roessler and A. Katterfeld, "DEM parameter calibration of cohesive bulk materials using a simple angle of repose test," Particuology, vol. 45, pp. 105-115, 2019.

[31] X. Zhang, Z. Li, Z. Zhang, and Y. Li, "Discrete element analysis of the rheological characteristics of self-compacting concrete with irregularly shaped aggregate," Arabian Journal of Geosciences, vol. 11, no. 19, pp. 1-17, 2018.

[32] W. Cui, W.-s. Yan, H.-f. Song, and X.-1. Wu, "DEM simulation of SCC flow in L-Box set-up: influence of coarse aggregate shape on SCC flowability," Cement and Concrete Composites, vol. 109, p. 103558, 2020.

[33] U. Zafar, C. Hare, A. Hassanpour, and M. Ghadiri, "Drop test: a new method to measure the particle adhesion force," Powder Technology, vol. 264, pp. 236-241, 2014.

[34] B. M. Ghodki, M. Patel, R. Namdeo, and G. Carpenter, "Calibration of discrete element model parameters: soybeans," Computational Particle Mechanics, vol. 6, no. 1, pp. 3-10, 2018.

[35] S. H. Kwon, K. P. Jang, J. H. Kim, and S. P. Shah, "State of the art on prediction of concrete pumping," International Journal of Concrete Structures and Materials, vol. 10, no. S3, pp. 75-85, 2016.

[36] D. Feys, K. H. Khayat, A. Perez-Schell, and R. Khatib, "Development of a tribometer to characterize lubrication layer properties of self-consolidating concrete," Cement and Concrete Composites, vol. 54, pp. 40-52, 2014.

[37] K. L. Johnson, K. Kendall, and A. D. Roberts, "Surface energy and the contact of elastic solids," Proceedings of The Royal Society A, vol. 324, no. 1558, pp. 301-313, 1971.

[38] A. V. Rahul, M. Santhanam, H. Meena, and Z. Ghani, "3D printable concrete: Mixture design and test methods," Cement and Concrete Composites, vol. 97, pp. 13-23, 2019.

[39] K. El Cheikh, S. Rémond, N. Khalil, and G. Aouad, "Numerical and experimental studies of aggregate blocking in mortar extrusion," Construction and Building Materials, vol. 145, pp. 452-463, 2017.

[40] Z. Zhang, Y. Cui, D. H. Chan, and K. A. Taslagyan, "DEM simulation of shear vibrational fluidization of granular material," Granular Matter, vol. 20, no. 4, pp. 1-20, 2018.

[41] X. Gu, L. Lu, and J. Qian, "Discrete element modeling of the effect of particle size distribution on the small strain stiffness of granular soils," Particuology, vol. 32, pp. 21-29, 2017.
[42] G. K. P. Barrios, R. M. de Carvalho, A. Kwade, and L. M. Tavares, "Contact parameter estimation for DEM simulation of iron ore pellet handling," Powder Technology, vol. 248, pp. 84-93, 2013.

[43] Y. Li, J. Hao, C. Jin, Z. Wang, and J. Liu, "Simulation of the flowability of fresh concrete by discrete element method," Frontiers in Materials, vol. 7, 2021.

[44] A. P. Grima, Quantifying and Modelling Mechanisms of Flow in Cohesionless and Cohesive Granular Materials, University of Wollongong, Wollongong, Australia, 2011.

[45] J. Ai, J.-F. Chen, J. M. Rotter, and J. Y. Ooi, "Assessment of rolling resistance models in discrete element simulations," Powder Technology, vol. 206, no. 3, pp. 269-282, 2011.

[46] S. K. Wilkinson, S. A. Turnbull, Z. Yan, E. H. Stitt, and M. Marigo, "A parametric evaluation of powder flowability using a Freeman rheometer through statistical and sensitivity analysis: a discrete element method (DEM) study," Computers \& Chemical Engineering, vol. 97, pp. 161-174, 2017.

[47] E. Murphy and S. Subramaniam, "Binary collision outcomes for inelastic soft-sphere models with cohesion," Powder Technology, vol. 305, pp. 462-476, 2017.

[48] H. Hoornahad and E. A. B. Koenders, "Towards simulation of fresh granular-cement paste material behavior," Advanced Materials Research, vol. 295-297, pp. 2171-2177, 2011.

[49] J. H. Lee, J. H. Kim, and J. Y. Yoon, "Prediction of the yield stress of concrete considering the thickness of excess paste layer," Construction and Building Materials, vol. 173, pp. 411-418, 2018.

[50] ASTM C29/C29M, Standard Test Method for Bulk Density and Voids in Aggregate, ASTM C29/C29M, West Conshohocken, PA, USA, 1997.

[51] N. S. Klein, S. Cavalaro, A. Aguado, I. Segura, and B. Toralles, "The wetting water in cement-based materials: modeling and experimental validation," Construction and Building Materials, vol. 121, pp. 34-43, 2016.

[52] H. D. Le, E. H. Kadri, S. Aggoun, J. Vierendeels, P. Troch, and G. De Schutter, "Effect of lubrication layer on velocity profile of concrete in a pumping pipe," Materials and Structures, vol. 48, no. 12, pp. 3991-4003, 2015.

[53] E. Secrieru, J. Khodor, C. Schröfl, and V. Mechtcherine, "Formation of lubricating layer and flow type during pumping of cement-based materials," Construction and Building Materials, vol. 178, pp. 507-517, 2018.

[54] D. Kaplan, F. d. Larrard, and T. Sedran, "Design of concrete pumping circuit," ACI Materials Journal, vol. 102, pp. 100117, 2005. 